\title{
Diversidade Sexual e de Gênero, Estado Nacional e Biopolítica no Sul Global: Lições da África
}

Sexual and Gender Diversity, National State and Biopolitics in the Global South: Lessons from Africa

\section{Fabiano Gontijo}

\section{(2) OpenEdition \\ Journals}

\section{Edição electrónica}

URL: https://journals.openedition.org/aa/8318

DOI: $10.4000 / a a .8318$

ISSN: 2357-738X

\section{Editora}

Programa de Pós-Graduação em Antropologia Social (UnB)

Edição impressa

Paginação: 66-96

ISSN: 0102-4302

\section{Refêrencia eletrónica}

Fabiano Gontijo, «Diversidade Sexual e de Gênero, Estado Nacional e Biopolítica no Sul Global: Lições da África», Anuário Antropológico [Online], v.46 n.2 | 2021, posto online no dia 30 maio 2021, consultado o 01 junho 2021. URL: http://journals.openedition.org/aa/8318; DOI: https://doi.org/10.4000/aa.8318

\section{(c) $)(9)$}

Anuário Antropológico is licensed under a Creative Commons Atribuição-Uso Não-Comercial-Proibição de realização de Obras Derivadas 4.0 International. 


\title{
anuário antropológico \\ v. $46 \cdot \mathrm{n}^{\circ} 2 \cdot \mathrm{majo-agosto} \cdot 2 \odot 21.2$
}

\section{Diversidade Sexual e de Gênero, Estado Nacional e Biopolítica no Sul Global: Lições da África}

\author{
Sexual and Gender Diversity, National State and Biopolitics in the Global South: \\ Lessons from Africa \\ DOI: https://doi.org/10.4000/aa.8318
}

\begin{abstract}
Fabiano Gontijo
Universidade Federal do Pará, Instituto de Filosofia e Ciências Humanas, Faculdade de

Ciências Sociais, Programa de Pós-Graduação em Antropologia, Belém, PA, Brasil

Professor Titular da Universidade Federal do Pará. Doutor em Antropologia, École des Hautes Études en Sciences Sociales. Bolsista de Produtividade, Conselho Nacional do Desenvolvimento Científico e Tecnológico.
\end{abstract}

Resumo: Nos últimos 25 anos, tem sido publicado um número de considerável de textos de autoria, em sua grande maioria, de pesquisadores/as africanos/as, tratando das expressões da diversidade sexual e de gênero no continente africano do ponto de vista das ciências sociais. Os textos têm em comum a relação que apresentam entre sexualidade, Estado nacional e globalização, contextualizados a partir dos efeitos do colonialismo, do imperialismo e do capitalismo. Trata-se aqui de apresentar ao público de leitores de língua portuguesa um breve resumo das principais ideias desenvolvidas em algumas dessas publicações, com o intuito de promover a necessidade de se produzirem reflexões comparativas sobre sexualidade no Sul Global.
In the last 25 years, a considerable number of texts by African researchers have been published dealing with the expressions of sexual and gender diversity on the African continent from the perspective of the social sciences. The texts have in common the relationship they present between sexuality, national state, and globalization, considering the effects of colonialism, imperialism, and capitalism. I intend here to present a summary of the main ideas developed in some of these publications to a public of Portuguese-speaking readers in order to promote some comparative reflections on sexuality in the Global South.

Keywords: Sexuality. Governmentality. Nationalism. Coloniality. Africa. 


\section{Apresentação}

O que se pode aprender com os estudos africanos sobre as expressões da diversidade sexual e de gênero? ${ }^{1}$ Desde a década de 1990, percebe-se uma profusão de publicações antropológicas críticas e reflexivas (e também sociológicas, históricas e literárias) sobre a temática da sexualidade no continente (e quase sempre associadas também à temática do gênero), em sua imensa maioria de autoria de pesquisadoras/es africanas/os. Em geral, essas publicações têm como cenário, de um lado, a ideia globalmente difundida de que a África pós-colonial é um ambiente homofóbico e, de outro, a ideia localmente disseminada de que as práticas e identidades sexuais não normativas e a "homossexualidade" são exógenas ao continente e teriam sido levadas para lá pelos processos de colonização árabe-muçulmano e europeu-cristão; e enfim, há ainda a acepção falaciosa de que as pessoas africanas são luxuriosas e seus corpos, objetos "naturalmente" eróticos (Epprecht, 2008a, 2008b; Mbisi, 2011). Essas publicações, assim, partem da denúncia do caráter ocidental demasiadamente universalista e regulador do primeiro argumento, do caráter nacionalizante excessivamente culturalista do segundo e do caráter racista e essencializador do último, ao considerar que, em todos os casos, não se atentaria para as particularidades das corporalidades e das expressões da diversidade sexual e de gênero no tão diversificado território africano, nem a sua relação com complexas dinâmicas culturais transnacionais contemporâneas (Hoad, 2007)2 .

Com efeito, a categoria "homossexualidade" pode ser tratada como exógena à história africana, já que foi forjada no contexto europeu de consolidação do Estado nacional moderno, oriunda das discursividades médico-científicas e jurídico-morais instituidoras da heteronormatividade, do dimorfismo sexual e da heterossexualidade compulsória como bases biopolíticas de sustentação das ideologias nacionais. Os dispositivos biopolíticos assim instituídos serviam para disciplinar os corpos em função da produção capitalista e da reprodução dos trabalhadores nas sociedades burguesas. Essas discursividades, sem deixarem de ser maquiadas pela moralidade religiosa e pastoral - embora, em teoria, se opusessem à teologia cristã -, contribuíram para a legitimação dos projetos expansionistas coloniais e imperialistas europeus e capitalistas euro-norte-americanos ao longo dos séculos XIX e XX, imbuídos de uma declarada missão civilizatória (Elias, 1994) e disciplinadora dos corpos sob os auspícios da governamentalidade moderna (Foucault, 2004a, 2004b) ${ }^{3}$.

A descolonização e a "nova ordem mundial" do sistema-mundo (Wallerstein, 2006), a partir da segunda metade do século XX, levaram as nações africanas à adoção do modelo estatal ocidental com a manutenção de boa parte de sua estruturação ideológica baseada naqueles dispositivos biopolíticos da governamentalidade moderna. Isso foi feito com significativas nuances, inclusive a conservação da moralidade religiosa da colonização, donde a defesa, por parte desses novos governantes e das instituições de governo, da suposta exogenia da diversidade sexual e de gênero e o conseguinte desenvolvimento
1 Agradeço a Igor Erick (Doutorando, PPGA/UFPA) pelos comentários preciosos e ao Conselho Nacional de Desenvolvimento Científico e Tecnológico pela Bolsa de Produtividade em Pesquisa.

2 Será usada a expressão experiências da diversidade sexual e de gênero para se referir às práticas e identidades sexuais e/ou de gênero e suas múltiplas dinâmicas sociais e culturais (às vezes será usado o termo "expressão" da diversidade sexual e de gênero para dar ênfase ao caráter eloquente e vivaz das práticas e identidades); sexualidade não normativa designa as experiências da diversidade sexual e de gênero consideradas localmente como não correspondendo às expectativas sociais, morais e, às vezes, jurídicas estabelecidas e, portanto, passíveis de alguma forma de regulação; e enfim, sexualidade alternativa, quando as experiências são "outras" em relação às normativas, mas não necessariamente passíveis de enquadramento. Homossexualidade (assim como os termos lésbicas, gays, bissexuais, transsexuais, transgêneres, intersexual, etc) é o termo ocidental mais usado pelas instâncias internacionais (algumas organizações não governamentais, Organização das Nações Unidas, União Africana, etc.), também amplamente usado por governantes africanos e por ativistas, dentre outros.

3 Por governamentalidade, Foucault (2004a, p. 111-112) entende "[...] o conjunto constituído pelas instituições, procedimentos, análises e reflexões, cálculos e táticas que permitem exercer uma forma bem específica, embora muito complexa, de poder que tem por alvo principal a população, [tem] por forma maior de saber a economia política, [tem] por instrumento técnico essencial os dispositivos de segurança [...]"; e "[...] a tendência, o cabo 
de propósitos homofóbicos ${ }^{4}$.

Parte das elites nacionais africanas pós-coloniais, em acordo com a lógica do sistema-mundo moderno direcionada a partir do Norte Global, viram-se diante da injunção de reforçar a metafísica da diferença (Mbembe, 2000, 2001), ou seja, o particularismo da experiência africana comum ou a singularidade continental excepcional em relação ao resto do planeta. Isso se deu, inclusive, tanto ao naturalizar a subordinação universal das mulheres e essencializar o patriarcalismo primordial africano (o que foi denunciado por Oyěwùmí, 1997, com o contraponto de Bakare-Yusuf, 2003), quanto ao invisibilizar as práticas e identidades sexuais tradicionalmente vigentes e questionar as novas expressões da diversidade sexual e de gênero relacionadas às dinâmicas culturais transnacionais contemporâneas (o que foi denunciado por Mbisi, 2011).

O que as publicações recentes sobre a diversidade sexual e de gênero no continente vêm mostrando é precisamente as maneiras criativas de contraposição de uma epistemologia das resistências (Dorlin, 2009) às epistemologias europeias da sexualidade (Jaunait et al., 2013). Desse modo, faz-se frente aos efeitos nefastos da metafísica da diferença e a uma de suas principais prerrogativas, caracterizada por Mbembe (2006) como o potentat sexuel, ou seja, um regime de verdade falocrático com persistentes pressupostos morais do colonialismo, marcadamente cristãos e islâmicos.

As publicações sobre sexualidade em contextos africanos têm produzido teorizações críticas e reflexivas confrontadoras dos arbitrários culturais heteronormativos (sobretudo os arbitrários de origem colonial, mas não somente) que perduram nos projetos nacionais vigentes no continente e materializados nos discursos de líderes políticos, religiosos e juristas. Por outro lado, permitem ainda cotejar as novas formas de universalismos neoliberais de instituições internacionais (sobretudo, organizações não governamentais e instâncias da Organização das Nações Unidas) que, sob o pretexto de combate à AIDS ou à homofobia supostamente "natural" do continente, promovem ações consideradas como salvacionistas ou vitimizadoras perigosas.

O que chama a atenção é o fato de que essas publicações - resultantes de pesquisas empíricas, reflexões de ativistas e intervenções artísticas - parecem promover um diálogo bastante fértil entre as pessoas envolvidas em praticamente quase todo o continente, embora as reflexões sejam predominantemente produzidas a partir de países de língua inglesa. Chama atenção ainda a confluência dos propósitos críticos e reflexivos dessas publicações, apesar da diversidade de experiências históricas, vivências sociais, situações políticas ou impactos econômicos da inserção no sistema-mundo que configuram arranjos culturais bem peculiares a cada país.

Trata-se aqui de oferecer ao público leitor de língua portuguesa pequenos comentários gerais sobre algumas dessas publicações originalmente em línguas inglesa e francesa para provocar comparações entre essas pesquisas e aquelas realizadas nas Américas e alhures ${ }^{5}$. Para isso, apresentarei, num primeiro momento, uma breve reflexão sobre a construção histórica e antropológica dos corpos de força que, no Ocidente, não parou de conduzir, desde há muito tempo, em direção à preeminência desse tipo de poder chamado de "governo" sobre todos os outros [...]." Tradução livre do francês: "[...] l'ensemble constitué par les institutions, les procédures, analyses et réflexions, les calculs et les tactiques qui permettent d'exercer cette forme bien spécifique, quoique très complexe, de pouvoir qui a pour cible principale la population, pour forme majeure de savoir l'économie politique, pour instrument technique essentiel les dispositifs de sécurité [...]"; e "[...] la tendance, la ligne de force qui, dans tout l'Occident, n'a pas cessé de conduire, et depuis fort longtemps, vers la prééminence de ce type de pouvoir qu'on peut appeler le "gouvernement" sur tous les autres [...]." Por dispositivo, Foucault entende o conjunto heterogêneo que engloba "[...] discursos, instituições, organizações arquitetônicas, decisões regulamentares, leis, medidas administrativas, enunciados científicos, proposições filosóficas, morais, filantrópicas" (1998, p. 244) que pode ter por função estratégica a produção de verdades com efeitos de poder sobre os corpos, tornando-se assim biopolítico. A governamentalidade biopolítica seria, logo, esse governo peculiar dos corpos instituído pela modernidade ocidental.

4 Entende-se aqui por homofobia/lesbofobia/transfobia o conjunto dos efeitos de poder de discursos e atos preconceituosos e discriminatórios dirigidos às pessoas e coletivos que expressam sexualidades e identidades de gênero não normativas ou alternativas.

5 Frisa-se que não está nos objetivos desse artigo a elaboração das comparações, mas o de estimular leitoras/ es a realizarem-nas. No Brasil, os estudos sobre a diversidade sexual e de gênero têm 
africanos como abjetos, racializados, erotizados e exotizados, objetos paradoxais de desejo e de repúdio, mas sempre de controle, que teriam justificado, pela via do processo civilizatório, a colonização. A ideologia sexual racializada persiste até os dias de hoje como uma forma de ratificação da própria colonialidade. Em seguida, passarei à descrição de algumas das publicações mais instigantes sobre a diversidade sexual e de gênero em contextos africanos, que reagem à ideologia sexual racializada. A partir dessas publicações e relacionando-as timidamente com discussões produzidas em outras áreas, serão elaboradas algumas considerações sobre as relações entre Estado, nação, biopolítica e sexualidade no Sul Global, com o intuito de reforçar as reflexões sobre os "[...] principais discursos que dominam o debate sobre a homossexualidade, mostrando as raízes coloniais que, ainda, o atravessam." (Rea, 2018, p. 21), não somente no contexto africano, mas no Sul Global'.

\section{A ero/exotização dos corpos africanos como parte do dark continent discourse}

A partir dos séculos XV e XVI, culminando entre os séculos XVIII e XX, desenvolveram-se na Europa poderosas discursividades instauradoras de verdades sobre os corpos com a instituição das ciências biomédicas e as disciplinas jurídico-morais modernas (Foucault, 1995, 1999). Os conhecimentos instituídos contribuíram para legitimar os projetos expansionistas burgueses coloniais e imperialistas, ao produzir, naturalizar e justificar as hierarquias de raça, gênero e sexo que, até a atualidade, continuam compondo, essencializando e materializando, através dos corpos, a metafísica da diferença (Mbembe, 2000) e a diferença colonial e imperialista (Mignolo, 2011). Com isso, estabeleciam-se os corpos europeus brancos e viris como autênticos portadores da civilização, da racionalidade e da hombridade, enquanto os corpos não brancos, principalmente negros africanos e indígenas americanos, como corpos bestiais, emotivos ou frouxos (embora essa discurso fosse bastante ambíguo), sobre os quais deveria recair uma disciplina de controle e domesticação, abonando, desse modo, a submissão e/ou a escravização, agora sobre bases científicas e morais.

Embora a submissão e até mesmo a escravização baseadas em hierarquias raciais sejam anteriores ao colonialismo e ao imperialismo europeus e árabes (Moore, 2007; N’Diaye, 2006; Trabelsi, 2010, 2016), assim como o são o binarismo de gênero e a heteronormatividade (Fausto-Sterling, 2000), percebe-se, com base em Quijano (2000), Mgnolo (2008) e Foucault (1995, 2004b), que os dispositivos biopolíticos de governamentalidade instaurados pela modernidade europeia criaram e seguem impondo relações sociais bastante singulares de cunhos racial e sexual que particularizam a colonialidade. Forja-se, dessa maneira, a imagem do nègre-biologique-sexuel-sensuel-et-génital ${ }^{7}$, nas palavras de Fanon (1952: 163), que afiançaria a sexualização e a erotização da África (Subsaariana, mas não somente) como instrumento de poder a serviço da colonização (McClintok, 1995). Com a descolonização, a sexualidade e o controle dos corpos, assim como as discursividades médico-científicas e jurídico-morais de inspiração europeia, não deixariam privilegiado principalmente problemas, temas e discussões em torno das sociabilidades urbanas e/ou das construções identitárias, deixando de lado uma abordagem mais macrossociológica que daria conta da produção da heteronormatividade, por parte da biopolítica estatal e da geopolítica do sistema-mundo. Grande parte dos textos analisados nesse artigo, sobre realidades africanas, oferece conceitos e categorias interessantes para se refletir sobre as relações entre a diversidade sexual e de gênero, o Estado, os projetos nacionais e o sistema-mundo.

6 Não cabe apresentar aqui, de forma mais aprofundada, a discussão que dá origem às expressões Norte Global e Sul Global. Para os objetivos desse trabalho, considera-se o Norte Global como o conjunto de países globalizadores em suas ações de perpetuação do colonialismo e do imperialismo, por meio do capitalismo, enquanto o Sul Global é formado por países e regiões que reagem, de alguma forma, às imposições do Norte Global, às vezes produzindo criativamente novas formas políticas particulares e pautando alternativas globais contra o universalismo. Ver, a esse sujeito, Ballestrin (2017), Castro-Gómez (2019) e Santos (2007). Também não será apresentada aqui, de forma mais aprofundada, a discussão sobre a oposição entre Ocidente e Oriente, embora sejam utilizadas essas categorias ao longo do texto, mais ou menos como tratadas por Carrier (2003) e Said (1990).

7 Tradução livre do francês: "negro-biológico-sexual-sensual-e-genital". 
de ser instrumentos de poder, mas adquiririam outros significados, através, por exemplo, da continuidade da dominação masculina e do silenciamento de certas práticas sexuais e modos alternativos de subjetivação sexual (Amadiume, 2006; Ndjio, 2012; Nyanzi, 2011).

As discursividades médico-científicas europeias se expandiram como principais provedoras institucionalizadas de verdades sobre os corpos por todo o mundo em grande parte com base na elaboração de taxonomias raciais e sexuais (brancos $v s$. negros; heterossexuais $v s$. homossexuais, etc). Ao longo dos tempos, os conteúdos das discursividades podem até ter sofrido revisões e, com isso, as antigas taxonomias acabaram sendo oficialmente rejeitadas (ou ressignificadas?), mas seus efeitos reais ainda hoje se fazem sentir - não somente povoando imaginários, mas também servindo de parâmetros para políticas. No contexto da colonização francesa ${ }^{8}$, Peiretti-Courtis (2015) analisou a maneira como essas discursividades foram inscritas em manuais e tratados médicos que divulgavam aquelas taxonomias sob a forma de "etnologia somática" ou "história natural das raças" e até de "guias higiênicos" para viajantes. Através dessas discursividades, a invenção das raças e sua hierarquização caminhavam, desse modo, de mãos atadas com a naturalização da realidade teleológica do dimorfismo sexual e do binarismo de gênero e com os imperativos da reprodução "saudável" (Gontijo, 2018; Gontijo; Schaan, 2017) que sustenta(va)m as prerrogativas da colonialidade, como confirmado por Dorlin (2006, 2009) e Gargallo (2014). E assim, universalizava-se e essencializava, com base na hiperssexualização dos corpos africanos (Boëtsch e Savarese, 1999), o dark continent discourse, segundo Jungar e Oinas (2004).

Para ilustrar essa faceta do dark continent discourse, relembremos o caso de Sarah Baartman. Esse foi o nome dado pelos colonizadores a uma mulher khoikhoi, etnia chamada pejorativamente naqueles anos finais do século XVIII de "hotentote”. Foi levada de sua aldeia para a Cidade do Cabo, na África do Sul, então sob o domínio inglês, para trabalhar em residências e sítios particulares em condições de escravização. Em 1810, um cirurgião militar da marinha britânica, Alexander Dunlop, propôs ao patrão de Sarah, Hendrik Cesars, que ganhassem dinheiro exibindo-a em shows de aberrações em Londres. Chamava a atenção dos europeus a hipertrofia das nádegas (esteatopigia) e os lábios vaginais esticados (macroninfia), ambos os órgãos considerados mais salientes do que os de mulheres europeias. A partir de sua exibição entre 1810 e 1814, como um animal dentro de uma jaula em salas de espetáculo de Londres, foi apelidada ironicamente por jornalistas como a "Vênus Hotentote", termo que a consagraria posteriormente na literatura sensacionalista antropológica. Depois de uma breve passagem pela Holanda, passou a ser exposta em Paris a partir de 1814 por um comerciante de animais exóticos que cobrava para que as pessoas pudessem tocá-la. Era violentada com frequência, chegando a dar à luz uma criança que não sobreviveu. Pensadores da época, os mesmos "cientistas" que ficarão conhecidos por suas taxonomias raciais e sexuais, apressavam-se para analisá-la, alguns com autorização para proceder a experimentos sobre o seu corpo, como Georges Cuvier. Foi após o contato com Sarah que Cuvier e outros designaram as populações negras africanas como as "raças mais
8 Para o contexto britânico, ver Burton (1999), Han et al. (2018) e Levine (2007). 
inferiores" existentes - para alguns desses membros da nobreza francesa, Sarah representava uma espécie de elo perdido entre a animalidade e a humanidade.

Depois de sua morte em 1815, de causa nunca averiguada nem relatada, Sarah tornou-se mais ainda um objeto literal de especulações raci(ali)stas. Seu cadáver foi dissecado, a vulva, o ânus e o cérebro foram guardados em soluções de formol para pesquisas (e eventualmente exibidos como peças curiosas de museu), o esqueleto foi reconstituído por Cuvier e exposto permanentemente até 1974 juntamente com uma estátua de gesso em tamanho natural. A exposição de seus restos acontecia inicialmente no Muséum National d'Histoire Naturelle / Jardin des Plantes e, em seguida, no Musée de l’Homme, ambos em Paris, espaços em que sua estátua era exibida de costas, logo na entrada, para que os visitantes se impactassem com o que tornava Sarah tão bizarra e animalesca para os padrões raciológicos europeus, as suas nádegas. Pouco depois do fim do apartheid na África do Sul, os khoikhoi iniciaram uma mobilização popular para reforçar o pedido, iniciado na década de 1940, de restituição pelo governo francês dos restos mortais de Sarah, o que acabou acontecendo, não sem polêmicas, em 2002. Um ritual funerário foi então realizado na região da Cidade do Cabo para acolher os restos - porém, o cérebro, o ânus e a vulva teriam se perdido (!!) nas reservas técnicas francesas (Abrahams, 2003; Bancel et al., 2014; Blanckaert, 2014; Dias e Belizze, 2020; Ferreira e Hamlin, 2010; Gordon-Chipembere, 2011; Holmes, 2009; Qureshi, 2004). A história de Sarah não foi um caso isolado: até a década de 1930, centenas de pessoas não europeias foram exibidas, quase sempre à força, em zoológicos humanos (como no Jardin d'Acclimatation, em Paris), exposições coloniais e exposições universais na Europa e nos Estados Unidos para robustecer a ideologia da supremacia branca e da conseguinte inferioridade dos povos não europeus e sancionar, assim, o colonialismo e o imperialismo, agora com suposta base científica (Bancel et al., 2002) ${ }^{9}$.

Pouco mais de dois séculos depois do terror infligido a Sarah, mais uma faceta do dark continent discourse se desvendaria, também na França, com a polêmica gerada em torno das publicações em 2018 e 2019 de duas coletâneas: Sexe, Race $\mathcal{E}$ Colonies: la domination des corps du XVesiècle à nos jours (Sexo, raça e colônias: a dominação dos corpos do século XV aos dias de hoje), organizada por Blanchard, Bancel, Boëtsch, Taraud e Thomas, com prefácio de Mbembe, publicado pela editora La Découverte em 2018; e, no ano seguinte, o mesmo grupo de autores, ao qual se juntaram Chalaye, Robles, Sharpley-Whiting, Staszak e Yahi assinaram Sexualités, Identités \& Corps Colonisés (Sexualidades, identidades \& corpos colonizados), publicado pela editora do Conseil National de la Recherche Scientifique (CNRS).

O primeiro livro partiu da maneira como sexualidade, dominação e colonização se emaranharam nas mentes europeias ao longo dos últimos seis séculos inventando um "outro" que deveria ser controlado através da apropriação de seu corpo e de seu território. A publicação contou com a contribuição de uma centena de historiadoras/es, antropólogas/os, sociólogas/os, cientistas políticas/os, críticas/ os literárias/os, artistas, etc. de diversas nacionalidades que buscaram, com o auxílio de 1.200 ilustrações, dar conta do papel central que o sexo desempenha nas
9 Ver, sobre os zoológicos humanos, o documentário de Pascal Blanchard e Bruno Victor-Pujebel disponível em: https://www.youtube.com/ watch?v=pysovxQbfw8 
relações de poder coloniais (passadas e persistentes). Tentou-se, com a publicação, trazer a público documentos visuais que fabricaram o olhar exótico e as fantasias eróticas ocidentais, reflexos da dominação racial e sexual colonial e pós-colonial. Os textos ajudaram a compreender o contexto de produção das imagens, de sua difusão e recepção, assim como a importância da história visual para descolonizar os olhares e desconstruir a ordem colonial que havia organizado a sexualidade com base em critérios raciais validados até mesmo pela ciência. O segundo livro continuou o empreendimento na tentativa de demonstrar que a sexualidade e as hierarquias raciais foram consubstanciais à administração do empreendimento colonial e à elaboração de imaginários transnacionais, inventando uma espécie de sexualidade hegemônica mundializada.

Centenas de reportagens, entrevistas, resenhas, programas de televisão e rádio e posts em redes sociais e blogs criaram um ambiente bastante negativo para a recepção dos livros, acusados de enaltecer a violência colonial contra as pessoas colonizadas e seus descendentes, espetacularizar desnecessariamente as relações sociais passadas (racializadas e sexualizadas), retomar rancores que já teriam sido bem resolvidos entre ex-colonizadores e ex-colonizados e, enfim, de serem manifestos pornográficos perpetuadores dos crimes sexuais que se pretendia denunciar (em razão do caráter voyeuriste que supostamente não teria levado em consideração as vítimas) ${ }^{10}$.

Por trás da virulência das críticas vindas de todos os espectros do gradiente político estava o medo de se tocar no assunto da "ideologia colonial" e suas heranças pós-coloniais ${ }^{11}$ ao escancarar a fratura social que se observa na França nos dias de hoje, quando, por exemplo, explodem as frequentes crises nas periferias urbanas francesas protagonizadas por pessoas negras e/ou de origem muçulmana. Perigosamente, isso denunciaria a fragilidade atual dos arbitrários culturais que ainda tentam sustentar o ardiloso projeto nacional (imperialista) francês. As críticas se relacionam ainda à dificuldade que os países colonizadores têm em lidar com o fato de que a sexualidade não foi apenas um aspecto marginal da colonização, mas uma parte fundamental do empreendimento colonial no passado e em seus desdobramentos neocoloniais inalteráveis na contemporaneidade - sob a forma, por exemplo, do que se pode designar como colonialidade bionecropolítica (Burton, 1999; Dorlin, 2009; Hyam, 1991; Levine, 2007; Lima, 2018; McClintok, 1995; Stoler, 1995, 2002) ${ }^{12}$.

$\mathrm{O}$ dark continent discourse assim produzido e reproduzido ad nauseam perpetuou a representação estereotipada das populações negras como naturalmente lascivas e a consequente necessidade de disciplinar os seus corpos através da hetenormatividade embutida no processo civilizatório europeu (Dorlin, 2009; Epprecht, 2008a). Com a descolonização da África, a Europa não era mais tão religiosa, a heteronormatividade já não se baseava nos mesmos princípios morais $\mathrm{e}$ o protagonismo feminino e as sexualidades alternativas deixavam de ser ameaças ao desenvolvimento do sistema-mundo idealizado a partir do Ocidente. Naquele momento, parte das elites africanas, de modo geral, adotavam as estruturas dos sistemas jurídicos e políticos e as ideologias religiosas de origem europeia para
10 Para algumas dessas críticas, ver, por exemplo: https://www.liberation.fr/ debats/2018/09/30/un-ouvrage-sans-ambition-scientifique_1682245, https://orientxxi. info/lu-vu-entendu/sexe-race-et-colonies-le-livre-corps-souille,2760 e https://www. arretsurimages.net/chroniques/ le-matinaute/sexe-race-et-colonies-pascal-blanchard-ne-veut-pas-debattre

11 O projeto acadêmico de Blanchard envolve, desde seu início, a revelação dos dispositivos contemporâneos que mantêm o que chama de "ideologia colonial" e "memória colonial" desafiadoras da velha concepção da cidadania francesa (Blanchard, 2005). Vale lembrar que a França é uma nação colonialista que preserva uma dezena de territórios e departamentos ultramarinos nos dias de hoje.

12 As perspectivas teóricas, metodológicas e epistemológicas críticas agrupadas sob a apelação de "pós-coloniais" (Loomba et al., 2005), em particular aquelas organizadas em torno dos subaltern studies indianos (Chakrabarty, 2002), da decolonialidade Africana/Negra ou crítica pan-africana (Malomalo, 2019; Mbembe, 2005) e da decolonialidade latino-americana (Lander, 2005; Maldonado-Torres, 2018) parecem gerar um certo desconforto no meio acadêmico europeu, como se pode notar nas depreciações de Amselle (2008). 
a conformação dos novos Estados nacionais do continente, como observado por Kaoma (2009) e Ndjio (2012), o que acarretou críticas severas por parte dos países ocidentais, agora em nome dos Direitos Humanos (Aderinto, 2014; Aldrich, 2003). Internamente, reações e formas criativas de resistência se intensificaram em diversos países africanos (Broqua, 2012; Duranti, 2008; Gaudio, 2009; Hayes, 2000; Matebeni, 2011), contrárias tanto às discursividades ocidentais instauradoras de uma nova ordem hegemônica (civilizacional, salvacionista e redencionista) que busca reforçar a história única denunciada por Adichie (2019), quanto às narrativas nacionalistas de cunho sexista e/ou homofóbico que negam a diversidade sexual e de gênero em África e instalam aquilo que Herdt (2009) chamou de pânico sexual como uma modalidade de pânico moral (Aarmo, 1999; Awondo, 2012; Awondo et al., 2013; Dudink, 2013; Guebeguo, 2006b; Gunkel, 2013; Ireland, 2013; Izugbara, 2004; M’Baye, 2013; Tamale, 2007).

\section{A diversidade sexual e de gênero africana em textos, pretextos e contextos}

As mudanças de perspectivas ocorridas nos países colonizadores europeus e nos Estados Unidos a partir de meados do século XX, representadas pela condenação das práticas raci(ali)stas e eugênicas e a paulatina revisão das concepções de gênero e sexualidade, e pela própria descolonização não ocorreram naturalmente por iniciativa dos governantes desses países, nem somente como o resultado de lu-

tas dos coletivos oprimidos e/ou colonizados. Foram fruto, sobretudo, das reações ao descontentamento generalizado em relação à ordem mundial opressora, o que levou, por exemplo, à criação da Organização das Nações Unidas e suas instâncias e à universalização da mensagem dos Direitos Humanos.

Mas, isso não teria acarretado um sistema-mundo sem opressões, e sim, um deslocamento ou redimensionamento das relações de poder (Dudink, 2013). Essas relações, baseadas em disciplinas jurídico-morais ocidentais, no ideal de justiça social e nos discursos dos Direitos Humanos se opõem ao que Jaunait et al. definiram como a hegemonia dos nacionalismos heterocentrados e supremacistas brancos e promovem, assim, a retórica da democracia sexual universal que reforça a impressão de uma sexualidade hegemônica mundializada (Jauanit et al., 2013). De acordo com Jackson (2009), se, por exemplo, judeus e homossexuais eram antes considerados como "raças" a serem banidas, agora passaram a ser componentes da diversidade cultural alegadamente inclusivista ocidental. Por oposição, os muçulmanos, considerados como fundamentalistas, e os africanos, considerados como tradicionalistas, tornaram-se perigosos, não mais sobre bases biológicas (a hierarquia racial), mas sobre bases culturais (o choque das civilizações), por supostamente desrespeitarem os Direitos Humanos.

As publicações das últimas três décadas sobre a diversidade sexual e de gênero no continente africano parecem despontar, nos contextos descritos acima, precisamente para dar conta das reações e formas criativas de resistência que pululam nos mais diversos países africanos como modos alternativos de lidar com 
as novas configurações do sistema-mundo contra o dark continent discourse e a história única. Antes de prosseguir com a breve exposição de uma seleção dessas publicações, é preciso apresentar algumas ponderações.

A heterogeneidade africana é considerável, seja cultural, política, econômica e histórica ou relativamente às configurações de produção de conhecimentos científicos e filosóficos, o que poderia dificultar qualquer tentativa de análise e comparação dessa produção. No entanto, desde a descolonização, tem sido feito um esforço exitoso no sentido de se elaborar perspectivas teóricas (e epistemopolíticas) que viabilizam as comparações transnacionais em nível continental (Mafeje, 2001; Mbembe, 2000; Malomalo, 2019; Mudimbe, 2013), como é o caso, por exemplo, das discussões promovidas no âmbito do Centro para o Desenvolvimento da Pesquisa em Ciências Sociais em África (CODESRIA) ${ }^{13}$. Ao apresentar as publicações sobre a diversidade sexual e de gênero em África, não problematizarei especificamente as questões relativas à maneira como se constituem essas perspectivas teóricas pan-africanas, afro-centradas, etc. ${ }^{14}$

As publicações recentes sobre sexualidades no continente são majoritariamente em língua inglesa, em particular os livros organizados ou coletâneas. Logo, representam muito mais os países subsaarianos de língua oficial inglesa, sobretudo África do Sul (e, em seguida, Camarões, Gana, Quênia, Malauí, Nigéria, Tanzânia, Uganda e Zimbábue), embora em algumas dessas publicações se discutam também realidades de países de línguas francesa ou árabe - em menor grau, portuguesa. Alguns dossiês em revistas e artigos em francês abordam, geralmente, as realidades de países de línguas oficiais francesa ou árabe, com maior frequência Senegal, Camarões, Costa do Marfim e Marrocos, ao passo que artigos, dissertações e teses em português tratam das realidades de países de língua oficial portuguesa, principalmente Moçambique e, um pouco menos, Cabo Verde - não foram encontrados coletâneas ou dossiês em língua portuguesa. As realidades do norte do continente, de países de língua oficial árabe, são com frequência estudadas em comparação com as realidades do Oriente Médio, devido à influência árabe e, por essa razão, serão tratadas de forma menor aqui. Não serão analisados tampouco os textos em língua portuguesa, por razão já dita acima ${ }^{15}$.

A literatura antropológica colonial apresenta, de forma mais ou menos insidiosa, alguns exemplos de práticas e identidades vinculadas à sexualidade nas mais diversas sociedades submetidas à colonização. Partindo de concepções, preocupações e ansiedades da própria sociedade do/a antropólogo/a, numa perspectiva funcional-estruturalista, as pesquisas trataram dessas práticas e identidades vinculando-as pudicamente, ora à necessidade de casamentos por falta de mulheres ou por falta de homens nas sociedades em questão, ora a rituais e atividades mágico-religiosas transitórias, e de forma mais tímida, às condições criadas pelos colonizadores, como a homossocialidade promovida pela situação do trabalho nas minas do sul do continente ou em cidades ${ }^{16}$. Ou seja, segundo Epprecht (2008b), a homossexualidade (termo usado por Epprecht para tratar da diversidade sexual e de gênero) era quase sempre retratada como uma imitação da heterossexualidade ou algo que informava sobre a normalidade/normatividade da heterossexualida-
13 O CODESRIA, sediado em Dacar, Senegal, foi a primeira instituição criada após a descolonização para congregar pesquisadores/as africanos/ as e fomentar a pesquisa na área de ciências sociais, com destacado protagonismo na proposta de teorias mais apropriadas às múltiplas realidades do continente, contribuindo significativamente para o desenvolvimento social da/na região. Gênero é uma temática de grande visibilidade nas pesquisas promovidas pelo CODESRIA, enquanto as pesquisas sobre sexualidade ainda são tímidas (quando não vinculadas diretamente a gênero). Ver: https://www.codesria.org. 14 Além do CODESRIA, há um conjunto de instituições de pesquisa e/ou de ativismo que promovem importantes discussões e estudos sobre gênero e sexualidade no continente, como o Human Sciences Research Council (http://www.hsrc. ac.za/en), sediado na África do Sul, o African Regional Sexuality Resource Center (http://www. arsrc.org), sediado na Nigéria, o Gays and Lesbians of Zimbabwe (https://galz.org) sediado no Zimbábue, ou o coletivo Femmes Sous Lois Musulmanes (http://www.wluml.org/fr), com forte ênfase em discussões e estudos sobre saúde reprodutiva e enfrentamento a doenças sexuais e violência. Para viabilizar uma reflexão sobre os discursos homofóbicos afrocentristas, ver Gilroy (2001) ou Bussotti e Tembe (2014).

15 Tem-se uma boa revisão dos textos disponíveis em língua portuguesa sobre sexualidades na dissertação (em Cabo Verde) e na tese de doutorado (em Moçambique) de Miguel (2014, 2019), assim como em alguns artigos de sua autoria (Miguel, 2016a, 2016b). Nota-se a escassez de estudos sobre a temática em São Tomé e Príncipe, Guiné-Bissau e em Angola. Alguns dossiês organizados em periódicos brasileiros também contêm artigos sobre a temática, não somente relativos a países de língua oficial portuguesa, mas 
de; quando começaram a se desenvolver formas mais modernas de subjetivação sexual nas cidades africanas, como consequência das dinâmicas econômicas de urbanização a partir do início do século XX, as/os antropólogas/os, de acordo com o autor, fizeram vista grossa, posto que essa realidade não correspondia a seus esquemas funcional-estruturalistas baseados preferencialmente na busca de determinações étnicas (Epprecht, 2005).

Os relatos contidos nessas primeiras pesquisas, alguns deles revisados nos dias de hoje por pesquisadoras/es africanas/os, ajudariam, como será visto mais adiante, por um lado, a demonstrar as complexas relações instauradas no período colonial com o silenciamento sistemático da diversidade sexual e de gênero e seu enquadramento em parâmetros heteronormativos ocidentais, demonstrando ainda por tabela a tradição histórica dessa diversidade no continente (Epprecht, 2005; Murray e Roscoe, 1998). Mas, por outro lado, essas pesquisas acabariam por reforçar, no período pós-colonial de formação dos Estados nacionais africanos, o que Epprecht (2008a) chamou de alegoria nacionalista da heterossexualidade exclusiva, ou seja, o uso político da ideia da exogenia da homossexualidade e a promoção da alegada heterossexualidade "naturalmente" africana (Amory, 1997; Guebeguo, 2006b; Hayes, 2000; Mbembe, 2006; Mbisi, 2011; Miescher, 2005; Ndjio, 2012; Ratele, 2008; Rebucini, 2013) ${ }^{17}$.

A partir daí, uma nova geração de pesquisadoras/es africanas/os, principalmente do sul do continente, sentiram-se desafiadas/os a enfrentar as alegorias homofóbicas e as representações heterossexistas e androcêntricas da identidade africana, expondo as suas próprias histórias de "coming out" (ou de suas/seus interlocutoras/es), segundo Epprecht (2008b, p. 62), e a “[...]buscar corajosamente evidências da diversidade do desejo sensual entre africanos[as], assim como podem [existir evidências dessa diversidade] entre pessoas de qualquer outro grupo no mundo"18 - tais como Achmat (1993), Donham (1998), GALZ (1995), Krouse (1993), Nkoli (1994), Mburu (2000), dentre outras/os. Entre as décadas de 1990 e 2010, inúmeros textos oriundos dessa perspectiva crítica e reflexiva seriam publicados, colocando em risco aquelas alegorias e a representação da hiper-heterossexualização africana e denunciando as limitações das categorias "homossexual", "bissexual" e "heterossexual" para a compreensão das realidades regionais, tais como, em ordem cronológica de lançamento, os livros organizados por Gevisser e Cameron (1995), Murray e Roscoe (1998), Blackwood e Wieringa (1999) ${ }^{19}$, Arnfred (2004), Morgan e Wieringa (2005), Cole et al. (2007), Reddy et al. (2009) ${ }^{20}$, Tamale (2011), Diesel (2011), Nyeck e Epprecht (2013), Ekine e Abbas (2013), Martin e Makhosazana (2013), Matebeni (2014), Sandfort et al. (2015), Lachheb (2016), Matebeni (2018) e Spronk e Hendriks (2020) e os dossiês organizados por Broqua (2012), Broqua et al. (2009), Epprecht (2009) e Guebeguo (2009), Blidon e Roux (2011) e Sandfort e Reddy (2013), além dos livros autorais de Hayes (2000), Hoad (2007), Epprecht (2008a, 2008b, 2013), Gaudio (2009), Kaoma (2009) e Gunkel (2010)21, dentre outros.

Em $1995^{22}$, foi publicado o livro pioneiro organizado por Gevisser e Cameron, tratando especificamente do contexto sul-africano num momento bastante conturbado do país ${ }^{23}$. Mas, sem dúvida, o primeiro livro organizado mais citado também em países de língua oficial inglesa, sobretudo África do Sul, como o dossiê publicado na Revista Estudos Feministas em 2019, organizado por Laura Moutinho (2019). Enfim, a obra de Rea vem contribuindo nos últimos anos para instigar reflexões sobre as sexualidades em contextos africanos (Rea, 2017, 2019), assim como o artigo de Langa (2018).

16 Para uma revisão dessa literatura, ver Epprecht (2008b), Guebeguo (2006b), Krouse (1993), Miguel (2019), Murray e Roscoe (1998) e Ombolo (1990).

17 Há muitos exemplos de personalidades políticas e até presidentes africanos que, nos últimos anos, vêm denunciando arbirtrariamente o caráter exógeno da homossexualidade no continente e afirmando que as práticas sexuais entre pessoas do mesmo sexo/ gênero são também contrárias aos preceitos morais das novas sociedades africanas, baseados no cristianismo (que, paradoxalmente, é realmente exógeno ao continente). Esses discursos acontecem, em geral, como reações à visibilização crescente das identidades com base na sexualidade - ver, para a análise desses discursos políticos e seus efeitos, Aarmo (1999), Awondo (2012), Awondo et al. (2013), Cheney (2012), Demange (2012), Guébeguo (2006a), Ireland (2013), Izugbara (2004), Larmarange et al. (2009), M'Baye (2013), Miguel (2019) e Spronk (2012). Ver, sobre um caso curioso no Gabão, o comentário de Paola Audrey em: https://www.youtube.com/ watch?v=9eUyzUFqpmc

18 Tradução livre do inglês: "[...] seek evidence of the diversity of sensual desire among Africans as they might among any other group of people in the world."

19 A coletânea organizada por Blackwood e Wieringa (1999) trata, em seus treze capítulos, das experiências de sexualidades não normativas de mulheres pelo mundo afora e apresenta dois textos fundamentais para as pesquisas em contexto africano: o capítulo 
quando se trata de pesquisas sobre as expressões da diversidade sexual e de gênero em diversos contextos africanos e, provavelmente, o que serviu direta ou indiretamente de inspiração para o desenvolvimento das pesquisas seguintes, foi aquele organizado e publicado em 1998 por Murray e Roscoe ${ }^{24}$. Os dois sociólogos/ antropólogos/ativistas estadunidenses - que tiveram um papel relevante na compilação de dezenas de textos sobre as sexualidades alternativas nos mais diversos lugares do planeta - reuniram nesse livro intitulado Boy-Wives and Female-Husbands: Studies in African homosexualities (Garotos-esposas e mulheres-maridos: estudos sobre as homossexualidades africanas ${ }^{25}$, um conjunto de mais de 20 textos, compreendendo artigos acadêmicos, memórias coloniais e relatos contemporâneos, inclusive de autoria de pesquisadores/as africanos/as, na tentativa de, primeiramente, questionar o mito das origens estrangeiras da homossexualidade em África e, assim, instigar investigações que dessem conta da multiplicidade das situações sociais africanas e dos "padrões de sexualidade entre pessoas do mesmo sexo" (1998, p. xviii). Para os organizadores, o "mito" da negação da diversidade sexual e de gênero africana difundido pelos europeus teria se tornado, no período pós-colonial, um "tabu" difundido pelos africanos, mas baseado em uma moralidade europeia. E afirmam:

Os colonizadores não introduziram a homossexualidade em África. Em vez disso, os europeus introduziram a intolerância à homossexualidade - e sistemas de vigilância e regulamentação para suprimi-la. Esses sistemas falharam porque a reação africana era a de esconder ou negar tais práticas. Somente quando os nativos começaram a esquecer que os padrões de relações entre pessoas de mesmo sexo faziam parte original de sua cultura é que a homossexualidade se tornou verdadeiramente estigmatizada. (Murray e Roscoe, 1998 , p. xvi $)^{26}$

A partir do recado acima dado por Murray e Roscoe e reforçado pelas/os demais autoras/es da coletânea, a produção africana sobre o tema decolou ao longo da década de 2000. No início da década, foi publicado o livro de Hayes (2000) intitulado Queer Nations: Marginal sexualities in the Maghreb (Nações queer: sexualidades marginais no Maghreb) sobre as insubordinações de gênero, sexualidades dissidentes e vivências sexuais marginais retratadas em obras literárias que iam na contramão dos projetos de nation-building vigentes no Marrocos, na Argélia e na Tunísia, antigas possessões francesas. As/Os escritoras/es citadas/os por Hayes vislumbravam uma luta anticolonial que resultaria na liberação sexual e em nações mais inclusivas, o que acabou não acontecendo. Esse livro, junto com a obra de Rebucini $(2009,2013)$ sobre o Marrocos e o livro organizado por Lachheb (2016) contendo doze capítulos sobre os três países do Maghreb e a diáspora norte-africana na França, dialogam muito mais com outras publicações tratando da diversidade sexual e de gênero em países islâmicos e o homo-islamicus (Lachheb, 2016) para além da África - por exemplo, com os textos contidos em Schmitt e Sofer (2013 [1992]) ou em Murray e Roscoe (1997) ou ainda o livro de Massad (2007) -, do que de Kendall aborda as relações tradicionais entre mulheres no Lesoto e o impacto atual da construção dos discursos lesbofóbicos ocidentais (a autora também teve um capítulo sobre o mesmo assunto na coletânea de Murray e Roscoe, 1998), ao passo que o texto de Aarmo mostra a maneira como mulheres lidam com a ideia da exogenia da homossexualidade no Zimbábue.

20 Trata-se de um livro sobre as políticas de enfrentamento à AIDS no contexto da África do Sul, com alguns capítulos resultantes de pesquisas comparativas realizadas em outros países de língua inglesa, tais como Malauí e Zimbábue.

21 A autora trata da maneira como a identidade sexual emergiu no discurso nacional pós-apartheid na África do Sul, fazendo do país o primeiro no continente a reconhecer os direitos de pessoas homossexuais ainda na década de 1990. Mas, Gunkel mostra que isso não quer dizer que há ampla aceitação das sexualidades não normativas no país, em razão da persistência da ideia da exogenia da homossexualidade e das modalidades vigentes dos discursos nacionalistas.

22 Há uma edição pela Editora Ravan, de Joanesburgo, datada de 1994.

23 Há um número muito grande de textos sobre a diversidade sexual e de gênero na África do Sul que não serão comentados aqui, pois dariam um artigo à parte, tais como Currier (2012), Matebeni (2011), Read (2013) ou Tucker (2009).

24 Recentemente, em homenagem aos 20 anos do livro, foi publicado um artigo (em formato de balanço) tratando de algumas importantes contribuições da obra para os estudos de sexualidade em África (Epprecht, Murray, Andam, Miguel, Mbaye e Gaudio, 2018).

25 O título parece dialogar diretamente com o livro, também pioneiro, de Amadiume (1987), Male Daughters, Female Husbands: Gender and sex 
com escritos analisando regiões de maioria islâmica na África Subsaariana - por exemplo, Gaudio (1998, 2009), Larmarange et al. (2009), M’Baye (2013), Niang et al. (2002) ou Teunis (2001). Enquanto os primeiros atestam com mais vigor o impacto do marcador religioso e os efeitos das colonizações árabe-muçulmana e europeia sobre as práticas e identidades sexualizadas, os últimos apontam para a relevância da religiosidade em sua relação com a etnicidade, a "tradição africana" e os efeitos da colonização europeia. Essa é a particularidade dos escritos sobre o tema nos contextos de maioria muçulmana do continente.

Em 2004, foi publicado Re-Thinking Sexualities in Africa (Re-pensando as sexualidades em África), organizado por Arnfred, tratando sobretudo da sexualidade feminina nos mais diversos contextos nacionais africanos em seus doze capítulos: partindo-se da crítica à maneira como as sexualidades africanas são socialmente construídas como outras em relação à modernidade, racionalidade e civilidade europeias, a primeira parte contém textos que questionam teoricamente a produção do dark continent discourse, enquanto a segunda apresenta pesquisas sobre os desejos realizadas em algumas áreas do continente invisibilizadas por pesquisadoras/ es do mainstream e, enfim, a última aborda as mudanças socioeconômicas em andamento que estão afetando diretamente as relações de gênero e as sexualidades.

A coletânea organizada em 2007 por Cole et al. sob o título Africa after Gender? (África após o gênero?) se propõe também a oferecer reflexões sobre as relações entre gênero e sexualidade a partir daquela alegada "alteridade" africana. Os dezesseis textos do livro abordam a volatilidade do conceito de gênero quando aplicado ao continente africano e a própria volatilidade dos gêneros com o surgimento de novos modelos de mulher, os espaços públicos e o ativismo femininos, as relações entre as subjetivações generificadas e as elaborações de identidades nacionais e, enfim, as masculinidades, a misoginia e a senioridade no contexto africano dito “pós-gênero". Percebe-se, nessas duas coletâneas, o caminho conjunto traçado pelos estudos de gênero e os de sexualidade no continente.

Tratando mais diretamente das sexualidades não normativas e alternativas, tem-se uma série de publicações a partir de 2005, como Tommy Boys, Lesbian Men and Ancestral Wives, organizado por Morgan e Wieringa, sobre as práticas e identidades sexuais e de gênero dissidentes de mulheres. Esse livro peculiar, fruto de uma atividade do congresso da International Association for the Study of Sexuality, Culture and Society (IASSCS), reúne dez textos elaborados por mulheres que, em seus respectivos países (África do Sul, Namíbia, Quênia, Suazilândia, Tanzânia, Uganda e Zimbábue), são ativistas dos Direitos Humanos e de associações "homossexuais" ou assistentes sociais e pesquisadoras. Foi pedido para que elas coletassem narrativas tratando das práticas homofóbicas e as táticas de manutenção do "segredo" e do "silêncio" adotadas pelas interlocutoras para a sobrevivência em ambiente hostil - Miguel (2016a, 2019) observou táticas semelhantes em suas pesquisas junto a homens em Moçambique e em Cabo Verde. A coletânea mostra, assim, algumas formas de relações tradicionais e institucionalizadas entre mulheres em algumas áreas do continente, as suas reivindicações de direitos sexuais e as emoções de quem resiste à opressão em suas comunidades. in an African society (Filhas masculinas, mulheres-maridos: gênero e sexo numa sociedade africana), que trata da maneira como as mulheres de uma determinada região rural da Nigéria tiveram seu status de poder transformado pelo colonialismo e pela religião e mantido no período pós-colonial pela sistema educacional; a autora sugere que as mulheres terceiro-mundistas devem desafiar politicamente os governos, denunciando os arbitrários culturais e históricos que sustentam os sistemas patriarcais para resgatar o poder que tinham antes da colonização, agora sobre novas bases. Os textos da autora (ver também Amadiume, 1997) fazem eco com os de Oyěwùmí (1997) ao propor um pensamento feminista africano crítico em relação aos feminismos branco e negro ocidentais. 26 Tradução livre do inglês: "The colonialists did not introduce homosexuality to Africa. Instead, the Europeans introduced intolerance of homosexuality - and systems of surveillance and regulation for suppressing it. These systems failed as long as the African reaction was to hide or deny such practices. Only when native people began to forget that same-sex patterns were ever a part of their culture did homosexuality become truly stigmatized." 
Muito importantes, em razão das historicidades e teorias críticas que ensejam, são o livros de Hoad (2007), intitulado African Intimacies: Race, Homosexuality, and Globalization (Intimidades africanas: raça, homossexualidade e globalização), e os dois livros de Epprecht (2008a, 2008b) - o primeiro intitulado Heterosexual Africa? The History of an Idea from the Age of Explorations to the Age of AIDS (Africa heterossexual? A história de uma ideia da era das explorações até a era da AIDS) e o segundo, Unspoken Facts: A History of Homosexualities in Africa (Fatos indiziveis: uma história das homossexualidades em África).

Hoad parte dos discursos proferidos por líderes políticos africanos sobre a "exogenia da homossexualidade" para propor uma análise crítica da produção antropológica, abarcando as genealogias das representações exageradas da "homossexualidade" africana (e das ideias de raça, sexo e nação) no contexto das experiências históricas do imperialismo, da descolonização e da globalização. Ele denuncia os problemas inerentes aos textos produzidos sobre a temática, ora na definição ou na ausência de definição do que se entende por "África”, ora na designação do que se define como "sexualidade" enquanto categoria analítica ou como "sexualidades" enquanto categoria classificatória, ora ainda na delimitação de "homossexualidade" ou "homossexualidades", inclusive nos textos contidos em Murray e Roscoe (1998) e em Arnfred (2004) ou mesmo na obra de Amadiume (1987), consideradas, no entanto, positivamente como pioneiras. Hoad avalia o caráter público que a sexualidade parece adquirir "naturalmente" no pensamento ocidental moderno - os prazeres corporificados, suas histórias e seus traumas, como já dizia Foucault (1999) -, que parece se contrapor às expressões da diversidade sexual e de gênero em África, marcadas pelo "segredo" e o "silêncio" - como também sugerido, além de Miguel (2019), por Morgan e Wieringa (2005). Enfim, o autor pode, a partir daí, estudar as representações históricas e literárias das intimidades entre homens, contextualizando-as à luz dos debates recentes sobre o "caráter exógeno da homossexualidade" e da necessidade de se discutir a sexualidade em África de modo geral em relação à epidemia de HIV/AIDS no continente.

Quanto aos livros de Epprecht, ambos (2008a, 2008b) denunciam o caráter heterossexista da produção etnográfica dos séculos XIX e XX que fez da África Subsaariana o lugar por excelência da negação da homossexualidade ao passar “[...] a impressão de que os africanos são praticamente únicos no mundo pela ausência de, a ignorância sobre ou a intolerância em relação às exceções às normas heterossexuais.” (2008a, p. 35) ${ }^{27}$. Durante o período colonial, a Europa condenava a homossexualidade, enquanto a sua prática era corriqueira em determinadas situações no continente africano. Quando a Europa passou a promover o discursos dos Direitos Humanos, inclusive nomeadamente o de pessoas homossexuais, a África foi acusada de desrespeitar os Direitos Humanos e, em particular, as sexualidades consideradas pelos europeus como não normativas, já que o continente continuou a ocupar o lugar privilegiado da alteridade absoluta e da exceção em relação à Europa. Recentemente, segundo o autor, pesquisadoras/es informadas/os pelo pós-estruturalismo, a crítica feminista e a teoria queer, após a descriminalização e a desestigmatização (parciais) da homossexualidade nas leis, na psiquiatria e na
27 Tradução livre do inglês:

"[...] the impression that Africans are virtually unique in the world in the absence of, ignorance about, or intolerance toward exceptions to the heterosexual norms." 
cultura popular no Ocidente, esforçaram-se em contrariar os estereótipos produzidos ao longo dos séculos. As novas pesquisas sobre as experiências da diversidade sexual e de gênero em contextos rituais e mágico-religiosos, paralelamente ao aparecimento dos grupos urbanos de ativistas abertamente "homossexuais" de inspiração ocidental contrários à homofobia estatal e religiosa, desafiam a cultura tradicional do "segredo" e do "silêncio". As/Os parceiras/os ocidentais dessas/es ativistas e agentes do novo cenário urbano se servem, em parte, dos estudos antropológicos coloniais para justificar a "homossexualidade" como algo naturalmente africano, mas, segundo Epprecht, sem muita crítica a essas pesquisas já datadas e marcadamente colonialistas ${ }^{28}$.

O protagonismo do empreendimento de Epprecht se nota ainda na organização, em 2009, do dossiê "New Perspectives on Sexualities in Africa" (Novas perspectivas sobre as sexualidades em África), juntamente com Guebeguo, publicado na revista Canadian Journal of African Studies, contendo artigos e resenhas em inglês e francês sobre viuvez e herança em Uganda, religião e prevenção à AIDS na Namíbia, sexualidades transacionais entre homens no Mali, ativismo homossexual, deficiência e AIDS na África do Sul, moralidade sexual e corporalidade no Quênia e, enfim, associativismo militante e direitos de pessoas homossexuais em Camarões. Os dois textos de apresentação dos organizadores (Epprecht, 2009; Guebeguo, 2009) configuram, juntos, uma revisão sobre as novas perspectivas das pesquisas no continente.

No mesmo ano, foi publicado também o dossiê "La Fabrique des Identités Sexuelles" ("A fábrica das identidades sexuais") no periódico Autrepart, organizado por Broqua e Eboko (2009), contendo artigos resultantes de pesquisas em diversos contextos do mundo, inclusive em países africanos, em particular sobre o enquadramento religioso das práticas sexuais na Etiópia, as percepções das esposas de homens que mantêm relações sexuais com outros homens no Senegal, as transações sexuais comercializadas em uma área turística do mesmo país, as transações sexuais comercializadas de mulheres no Marrocos, a concepção social da virilidade no Burkina Faso, as relações conjugais monetizadas no mesmo país, as identidades masculinas e femininas em tempos de globalização no Mali e, enfim, as "sexualidades transacionais" em meio urbano em Camarões.

Um outro dossiê seria organizado por Broqua em 2012, dessa vez especificamente sobre contextos africanos, na revista Politique Africaine ("L’Émergence des Minorités Sexuelles dans l'Espace Public en Afrique", "A emergência das minorias sexuais no espaço público em África”), contendo artigos sobre o papel dos cristãos evangélicos estadunidenses na configuração da moralidade sexual e na agenda política em Uganda, o heterossexismo no rap produzido no Gabão, mídia, política e homossexualidade em Camarões, a inserção da categoria "transgênero" no ativismo na Namíbia e na África do Sul, uma exposição artística sobre transgeneridade e justiça social no continente, além de um ensaio fotográfico e a tradução para o francês de uma parte do clássico "Inversão Sexual entre os Azande", de Evans-Pritchard, publicado originalmente no início da década de 1970.

Destacam-se ainda dois outros dossiês em periódicos. O primeiro, em francês,
28 Vale ressaltar a importância da obra de Kaoma, com diversos textos publicados a partir de 2009 tratando da relação entre religiosidade e sexualidade, com destaque para os efeitos dos avanços das igrejas cristãs neopentecostais estadunidenses, principalmente no contexto de Uganda (Kaoma, 2009). 
"(Géo)politique du Sexe” (“Geopolítica do sexo"), bem pequeno, foi organizado por Blidon e Roux (2011) e publicado na revista L'Espace Politique, compreendendo artigos sobre homossexualidade masculina e sobre a relação entre migração para o trabalho e sexualidade, ambos no Marrocos, e um sobre "identificações homossexuais" e tensões pós-coloniais em Camarões, além de artigos sobre sexualidade entre migrantes africanas/os na França. O segundo, em inglês, "African Same-Sex Sexualities and Gender-Diversity" ("Sexualidades de mesmo sexo e diversidade de gênero africanas”), foi organizado por Sandfort e Reddy (2013) e publicado na revista Culture, Health $\&$ Sexuality, contendo oito artigos e sete resenhas; os artigos se baseiam em estudos de caso realizados em países de língua oficial inglesa, tais como África do Sul, Botsuana, Camarões, Gana e Nigéria.

Na década de 2010, os livros organizados parecem trazer de forma mais explícita algum tipo de filiação à teoria queer estadunidense - sempre se levando em consideração as necessidades teóricas locais. Esse foi o caso, por exemplo, do Queer African Reader, publicado em 2013 sob a organização de Ekine e Abbas. O livro foi traduzido para o português, reorganizado e publicado recentemente em duas partes - a primeira por Rea, Paradis e Amancio (2018) e a segunda por Rea, Fonseca e Silva $(2020)^{29}$. Na segunda publicação em português, além de capítulos do Queer African Reader, encontram-se também alguns capítulos traduzidos de mais um importante livro publicado em 2014 sob a organização de Matebeni, Reclaiming Afrikan - Queer Perspectives on Sexual and Gender Identities (Recuperando Afrikan - perspectivas queer sobre identidades sexuais e de gênero). O livro organizado por Matebeni junta não somente textos acadêmicos, mas também ensaios críticos e artísticos. Em ambos os livros, trata-se de recobrar o caráter antinormativo da teoria queer, associando-o a uma reflexão sobre a identidade africana numa perspectiva anticolonial - donde o título do segundo livro - e à necessidade de se produzirem conhecimentos conectando produção acadêmica e artes ao ativismo. Em 2018, Matebeni organizou mais um livro com Moro e Reddy, dando continuidade ao seu projeto, Queer in Africa: LGBTQI Identities, Citizenship, and Activism (Queer em África: identidades LGBTQI, cidadania e ativismo), com textos de pesquisadores e ativistas de países de língua oficial inglesa do continente, principalmente da África do Sul.

Ainda na década de 2010, destacam-se os livros organizados por Tamale - African Sexualities: a Reader, publicado em 2011 -, Nyeck e Epprecht - Sexual Diversity in Africa: Politics, Theory, Citizenship (Diversidade sexual em África: politica, teoria, cidadania), de 2013 - e Sandfort, Simenel, Mwachiro e Reddy - Boldly Queer: African Perspectives on Same-Sex Sexuality and Gender Diversity (Audaciosamente queer: perspectivas africanas sobre sexualidade entre pessoas do mesmo sexo e diversidade de gênero), de 2015 -, além de mais um livro de autoria exclusiva de Epprecht - Sexuality and Social Justice in Africa, de $2013^{30}$.

O primeiro, com quase 700 páginas e mais de 60 capítulos de autoras/es de países de todas as partes do continente, junta reflexões teóricas e discussões acadêmicas com poemas, ensaios e textos de ativistas. O livro se inicia com reflexões relacionadas às particularidades das pesquisas sobre a diversidade sexual e de
29 Para comentários mais detalhados sobre o livro, ver as publicações de Rea $(2017,2019)$.
30 Merecem ser citados também os livros menos acadêmicos organizados por Diesel (2011) - que reúne narrativas biográficas, poemas, ensaios fotográficos e relatos sobre o universo lésbico sul-africano - e por Martin e Makhosazana (2013) - que contém contos literários retratando as experiências das sexualidades não normativas e alternativas em diversos contextos africanos. 
gênero no continente e a discussão de teorias particulares, passa por uma grande quantidade de temas (poder e políticas da sexualidade, representações sexuais e práticas identitárias, direitos reprodutivos, masculinidades, deficiência física e vulnerabilidade, AIDS, violência e homofobia e espiritualidade) e desemboca na proposta de "abordagens pedagógicas” para contrapor a percepção de que as sexualidades não normativas são exógenas e não condizentes com a realidade africana contemporânea. O livro organizado por Sandfort et al. (2015), fruto de um evento ocorrido em Nairobi em 2014, alinhado com os empreendimentos de Tamale (2011), Ekine e Abbas (2013) e Matebeni (2014) e Matebeni et al. (2018), compila textos, resumos de papers e ensaios fotográficos de acadêmicos e ativistas de diversas áreas da África (sobretudo, de língua oficial inglesa, tais como África do Sul, Botsuana, Nigéria, Quênia e Uganda), em grande parte que se consideram como queers, gays, lésbicas, homossexuais etc.

Já o livro organizado por Nyeck e Epprecht (2013) conta com pouco mais de dez capítulos com os resultados de pesquisas - realizadas em Camarões, Gâmbia, Gana, Mali e ênfase especial para a África do Sul -, em torno da necessidade de se descolonizarem as representações ocidentais para se compreender "[...] a natureza complexa e multifacetada da sexualidade, das práticas sexuais e das performances de gênero em África.” (Nyeck e Epprecht, 2013, p. 5) ${ }^{31}$. Por sua vez, o livro datado do mesmo ano de autoria exclusiva de Epprecht apresenta mais uma boa revisão dos estudos sobre sexualidade no continente, uma importante discussão sobre as relações entre Estado, Igrejas e sexualidade e uma reflexão propositiva com as estratégias para as lutas por justiça social. Os quatro principais argumentos sustentados pelo autor são: as sexualidades não normativas não são exógenas ao continente; os "segredos" e "silêncios" corriqueiros sobre as experiências sexuais e afetivas podem ser revelados e as tradições podem ser modificadas sem que a “civilização africana” pereça; direitos humanos para as "minorias sexuais" podem beneficiar toda a população; e o excessivo foco em aspectos negativos dos modos de vida africanos (por parte, mas não somente, por exemplo, de organizações internacionais que globalizam a luta contra a homofobia sem se dar conta das particularidades locais) acabam prejudicando, mais do que contribuindo para, a reivindicação local por direitos e justiça.

Epprecht (2013) propõe que se fale mais de justiça social do que de direitos, pois a ideia de direitos sugere litígio, protesto, Estado e economia política, enquanto a ideia de justiça sugere negociação, educação e o papel da cultura na validação da desigualdade. Propõe que se fale de justiça erótica, a partir de Ellison (1996) e Kapur (2005), mais do que de direitos sexuais ou justiça sexual, pois “[...] os privilégios históricos por classe, raça e gênero não só foram incorporados pela economia política capitalista ao longo de centenas de anos de globalização desigual, como são agora profundamente incorporados por noções culturais sobre o que é e o que não é sexual." (Epprecht, 2013, p. 34) ${ }^{32}$. A partir do contexto africano e da maneira como as sexualidades aparecem de forma central nos debates políticos, Epprecht sugere ainda, seguindo a proposta de Ellison (1996, p. 114), uma ética libertadora da sexualidade como base para a necessária justiça erótica que tribu-
31 Tradução livre do inglês: "[...] complex, multifaceted nature of sexuality, sexual practices, and gender performance in Africa."

32 Tradução livre do inglês: "[...] historical privileges by class, race and gender have not only been built into the capitalist political economy over hundred of years of unequal globalization, they are now very densely built into cultural notions about what is and is not sexy." 
te para a abolição dos efeitos de poder opressores produzidos pelos dispositivos biopolíticos da governamentalidade em vigor no continente em associação com injunções ocidentais.

Mais recentemente, uma última coletânea foi publicada em inglês, organizada por Spronk e Hendriks (2020), contendo 24 textos divididos em seis partes (representações das sexualidades africanas; biopolítica e saúde sexual; identidades generificadas e práticas sexuais entre pessoas do mesmo sexo; sexualidades transacionais; religiosidade e tradição; e agências e prazeres). O livro conta com resultados de pesquisas recentes em diversas áreas do continente (tanto de língua oficial inglesa, quanto de língua oficial francesa), mas também com alguns textos já publicados de autoria de antropólogos considerados com “clássicos”, tais como Evans-Pritchard e Herskovits.

Em síntese, a década de 1990 apresentou uma produção bibliográfica baseada principalmente em relatos pessoais das experiências da diversidade sexual e de gênero de pessoas africanas que resolveram descrever pedagogicamente o seu "coming out", enquanto a década de 2000 reforçou a proposta presente no livro de Murray e Roscoe (1998) de produzir reflexões críticas sobre a suposta exogenia da homossexualidade e sobre a alegada homofobia "natural" no/do continente. A década de 2010 foi marcada pela adaptação de algumas questões da teoria queer às particularidades históricas, sociais e culturais africanas, pelo desenvolvimento de abordagens mais transnacionais e, enfim, pela elaboração de uma perspectiva que pode ser definida por decolonialidade africana/negra (Malomalo, 2019) ou queer pós-colonial (Rea, 2017).

\section{Perspectivas}

Afinal, que lições se podem tirar dos estudos africanos sobre as experiências da diversidade sexual e de gênero para a compreensão de outras realidades? Essas lições podem se depreender diretamente daquilo que os estudos, em maior ou menor grau, têm em comum: 1) o caráter questionador em relação à formação e à configuração dos Estados e projetos nacionais; 2) a postura crítica em relação às organizações e instituições internacionais de defesa e promoção dos Direitos Humanos e suas ações no continente; e 3) como corolário, a necessidade de se produzirem reflexões sobre as particularidades locais em suas conexões com as ideologias de nation-building (e a estruturação biopolítica da governamentalidade) de um lado e, de outro, em suas conexões com o contexto internacional das chamadas "guerras culturais globais" (Kaoma, 2009; Sandfort et al., 2015).

Balibar (1988) sugere que os Estados nacionais modernos são produtos da colonização, pois que todos foram colonizados ou colonizadores de alguma forma, ou os dois ao mesmo tempo. Esses Estados se universalizaram com o expansionismo europeu entre os séculos XVI e XX, baseando-se, como apontado por Quijano (2000) e Wallerstein (2006), na exploração - colonial, imperial e capitalista - de uma maioria por uma minoria, por meio do controle bio(necro)político dos corpos através dos regimes de verdade instauradores da ideologia e da hierarquia 
raciais, do binarismo de gênero e da heteronormatividade, dentre outros dispositivos sustentados por e sustentadores das discursividades médico-científicas e jurídico-morais ocidentais (Agamben, 1995; Foucault, 2004a, 2004b; Mbembe, 2018). Desse modo, o Estado se relaciona com a sexualidade elaborando as tecnologias de poder/saber da governamentalidade que servirão para o controle da população e de seus corpos por meio de mecanismos de segurança e de coerção situados em um território (Foucault 2004a, 2004b).

Os Estados nacionais ocidentais serão considerados como "civilizados" por defenderem o ideal dos Direitos Humanos e as liberdades individuais e agenciarem até mesmo algumas formas identitárias baseadas nas experiências da diversidade sexual e de gênero, sempre em nome da verdade cientifica e da segurança jurídica. Sendo assim, os Estados não ocidentais serão designados como "incivilizados" por manterem a população ou parte dela sob o jugo de mecanismos violentos de segurança para garantir a integridade soberana do território nacional, grande parte das vezes legitimando o uso da coerção em nome da religião e da tradição. Os primeiros são vistos como os portadores da felicidade universal, ao passo que os últimos são vistos como "outros", promotores do ódio; e assim se normaliza a branquitude como expressão "natural” da civilização e dos "verdadeiros" valores humanos (Dabashi, 2011).

A relação entre Estado e sexualidade mediada pelo controle social não seria exclusiva dos regimes políticos considerados pelos Estados ocidentais como opressores, mas estaria na base existencial de todos os Estados nacionais, inclusive ocidentais, sempre criadores de algum tipo de homo sexualis, assim como instituíram os "legítimos" homo œeconomicus, homo politicus, homo religiosus, enfim, o homo nationalis... modernos e ocidentais. Precisamente, os estudos africanos sobre sexualidade parecem ter como marca o forte interesse pela formação desse homo sexualis conectado ao homo nationalis. Puri (2004), retomando as obras de pesquisadoras/es que analisaram a relação entre Estado e sexualidade, percebeu a recorrência do tema do controle efetuado pelo Estado sobre os mais diversos aspectos da vida privada, ao delimitar os contornos - variáveis - das ditas "sexualidades respeitáveis”. Por se tratar de invenção ocidental, o conceito de identidade sexual, segundo Vanita (2002), ganhou o mundo através do expansionismo europeu com significados particulares a cada contexto cultural, em razão das configurações locais das relações de poder definidoras dos regimes de verdade, dispositivos biopolíticos e mecanismos institucionais e ideológicos de controle social dos corpos que determinam localmente o que é "normal" e o que é "abjeto" e que instituem e reforçam as desigualdades de gênero, classe, raça, etc - em breve, em razão das formas locais da colonialidade/imperialidade do poder/saber (Ballestrín, 2017; Gontijo, 2018a, 2018b; Quijano, 2002; Lander, 2005; Tamale, 2011).

Das e Poole (2004), tratando das relações que o Estado estabelece com as pessoas silenciadas e enquadradas, propõem uma etnografia das práticas, lugares e linguagens considerados como às margens do Estado nacional, ou seja, do modo como “[...] as práticas e as políticas da vida nessas áreas moldaram as práticas políticas, regulatórias e disciplinares que constituem, de alguma forma, aquilo 
que chamamos de 'Estado'.”33 (2004, p. 3). Para as autoras, essas pessoas foram definidas como “[...] excluídas das - ou opostas às - formas da racionalidade administrativa, da ordem política e da autoridade consignadas ao Estado." ${ }^{34}$ (2004, p. 5). Assim, o Estado se apresenta como o locus da ordem e, por conseguinte, as suas margens seriam o lugar da desordem, sobre as quais recairia a força do uso legítimo da violência estatal (física e simbólica) com a finalidade de impor a ordem "cultural”, controlar e domesticar o "estado de natureza" vigente ali. Mas, segundo as pesquisadoras, nas margens, a ação do Estado pode ser predada pelos sujeitos e assim, usada a serviço da sua sobrevivência política e econômica, como se percebe, por exemplo, nas formas contraculturais de questionamento do Estado e de negociação de existências alternativas e não normativas, como apontam muito bem as/os autoras/es africanas/os em suas obras sobre sexualidade (Tamale, 2011).

Informada pelos mecanismos que estão na base da colonialidade/imperialidade do poder/saber estruturadores da diferença colonial e dos colonialismos internos (Cardoso de Oliveira, 1993; Lander, 2005) e consciente do potencial heurístico desprovincializador do fazer antropológico do ponto de vista do Sul Global (Chakrabarty, 2007; Mafeje, 2001, 2008; Restrepo; Escobar, 2005), a antropologia e as ciências sociais brasileiras de forma geral poderiam analisar, a partir das margens do Estado, as formas originais de resistência criativa aos saberes, discursos, práticas e poderes disciplinares religiosos, médicos e jurídicos que foram naturalizados e se tornaram hegemônicos no Brasil. Isso é o que nossos/as colegas de alguns países africanos vêm fazendo com muito rigor. Assim, a antropologia e as ciências sociais poderiam ajudar a compreender como se estabeleceram os projetos de governamentalidade instituidores do Estado nacional e legitimadores de formas do que se pode chamar de colonialidade bionecropolítica... e poderiam ainda reforçar as reações anti- e contra-hegemônicas e decoloniais consequentes (Dudink, 2013; Epprecht, 2013; Jaunait et al., 2013; Tamale, 2011).

Uma outra marca importante dos estudos africanos sobre sexualidade parece ser a tentativa - exitosa - de produzir conhecimentos que, mesmo partindo de realidades nacionais, possam contribuir para reflexões comparativas transnacionais em nível continental. Com todas as devidas ressalvas sobre a heterogeneidade do continente (Hoad, 2007; Malomalo, 2019) e cautelosos em relação aos perigos da história única (Adichie, 2019) e da metafísica da diferença (Mbembe, 2000), esses estudos ecoam um esforço conjunto de se compreenderem as realidades locais a partir de sua inserção em um âmbito maior que tem como característica principal uma história social e política ligada aos efeitos do colonialismo, do imperialismo e do capitalismo/neoliberalismo configuradores do sistema-mundo (Wallerstein, 2006; Woltersdoff, 2006/7). Muitos desses estudos, por exemplo, abordam as particularidades locais de países, regiões ou grupos étnicos no que diz respeito às "sexualidades", "homossexualidades" ou "identidades sexuais e de gênero", com esses termos sempre no plural, para dar ênfase ao fato de que se trata de uma realidade diversa e complexa, mas sem deixar de relacionar essa diversidade a um substrato "africano" ou à sua localização après tout em África. Nos estudos sobre sexualidades em países da América Latina, vê-se raramente essa preocupação em
33 Tradução livre do inglês: "[...] the practices and politics of life in these areas shaped the political, regulatory, and disciplinary practices that constitute, somehow, that thing we call 'state.".

34 Tradução livre do inglês:

"[...] excluded from, or opposed to, the forms of administrative rationality, political order, and authority consigned to the state." 
promover análises transnacionais, principalmente no Brasil, e parece haver até mesmo uma desconfiança em relação aos poucos estudos que se aventuraram em produzir reflexões comparativas entre realidades regionais ou nacionais, como feito por Murray (1995) ou Gontijo, Arisi e Fernandes (2021).

Enfim, destaca-se aqui mais um elemento dos estudos africanos sobre sexualidade: a maneira como relacionam as configurações nacionais e os ideais continentais à crítica às ações globais promovidas por agências e instituições internacionais, tais como organizações não governamentais e a Organização das Nações Unidas e suas diversas instâncias, geralmente sediadas em países ocidentais. Para existir enquanto instrumento de governo, que promove a felicidade para alguns e a limita para outros, os grupos dominantes à frente do Estado precisam forjar uma base simbólica que acomode suas práticas de poder de modo a não serem questionados, a saber, uma ideologia nacional atribuidora de sentidos às tecnologias de poder/saber e aos dispositivos biopolíticos estatais (Dudink, 2013; Jaunait et al., 2013). Entram em cena, em alguns países, formas de nacionalismos homonormativos e homonacionalismos, ou seja, a maneira como alguns Estados ocidentais incorporam situacionalmente a defesa de certas experiências dissidentes da sexualidade a sua ideologia nacional e à expansão internacional de seus interesses, em detrimento de outras formas experienciais (Puar, 2007).

Após os eventos de 11 de setembro de 2001, segundo Puar (2007), os Estados Unidos e alguns países europeus, na deflagração da "guerra ao terrorismo", teriam se servido da defesa dos Direitos Humanos e particularmente dos direitos identitários "homossexuais" para legitimar a difusão de uma imagem cada vez mais positiva do Ocidente e contra os povos islâmicos (Massad, 2002, 2007). Esses países desenvolveram uma política representacional hegemônica como um forma de se mostrar mais "civilizados", guardiães dos direitos primordiais de todos os seres humanos, em relação a nações definidas, portanto, como "incivilizadas" que supostamente promoviam o terrorismo e não respeitavam sequer a diversidade sexual e de gênero humana. Ao fazê-lo, no entanto, segundo Puar (2007), ocultavam-se totalmente as tensões internas a cada país ocidental relacionadas aos modos múltiplos de se experimentar a sexualidade localmente e silenciava-se o tratamento diferenciado dado pelo Estado, através dos dispositivos biopolíticos, a essa multiplicidade, valorizando uma certa "sexualidade respeitável" em detrimento de todas as outras formas. A autora, no contexto estadunidense, questiona a política representacional hegemônica estabelecida em associação com aquilo que combina melhor com os anseios do Estado, gerando, dessa maneira, ações marcadas pelo que chama de homonacionalismo.

A partir daí, organizações não governamentais ocidentais, assim como agências internacionais de fomento ao desenvolvimento econômico, de promoção de governança ou de combate a doenças sexualmente transmissíveis, passariam a condicionar as suas ações voltadas para regiões e países do Sul Global em função do nível local de respeito aos chamados direitos homossexuais (Jaunait $e t$ al., 2013) e de adequação às formas ocidentais de comunidade sexual imaginada (Jackson, 2009), muitas vezes desconsiderando-se (ou considerando-se somente 
parcialmente) as expressões locais da sexualidade e a maneira como se inserem nas complexas configurações políticas nacionais (Massad, 2002, 2007). Correr-se-ia o risco, assim, de reforçar dicotomias falaciosas que instituem arbitrariamente centros "civilizados" e margens "incivilizadas", naturalizar a superioridade do projeto ocidental universalista, regulador e homonacionalista sobre os culturalismos identitários nacionalistas do Sul Global e essencializar a alegada incompatibilidade da modernidade com o tradicionalismo "tipicamente" terceiro-mundista. Enfim, as diferenças entre os projetos nacionais mundiais conflitantes seriam assim transfiguradas em diferenças sexuais, tornando-se mais um importante instrumento de controle do Sul Global pelo Ocidente em nível mundial, como bem denunciado pelos estudos africanos citados acima (Epprecht, 2013; Hoad, 2007). Essa é mais uma temática pouco abordada nos estudos sobre sexualidade produzidos na América Latina.

Em conclusão, as pesquisas realizadas em contextos africanos, ao proporem o que Dorlin (2009) define como epistemologias da resistência contra as epistemologias sexuais hegemônicas mundializadas, indicam pistas que podem ser levadas em consideração para se produzirem conhecimentos críticos e reflexivos capazes de contribuir para minimizar os efeitos perversos da persistente colonialidade bio(necro)política, além de contribuir ainda para a dissolução, como sugerido por Arnfred (2004) ou Wieringa e Sivorí (2013), de sistemas binários heteronormativos opressores. Ficam as dicas para a antropologia e as ciências sociais brasileiras. 


\section{Referências}

AARMO, Margrethe. How Homosexuality Became "Un-African": The case of Zimbabwe. In: BLACKWOOD, Evelyn; WIERINGA, Saskia W. (Orgs.). Female Desires. New York: Columbia University Press, 1999.

ABRAHAMS, Yvette. Colonialism, Dysfunction and Disjuncture: Sarah Bartmann's resistance (remix). Agenda: Empowering Women for Gender Equity, v. 17, n. 58, p. 12-26, 2003. Disponível em: https://www.tandfonline.com/doi/abs/10.1080/10130950.2003. 9674488. Acesso em: 5 de maio de 2020.

ACHMAT, Zackie. "Apostles of Civilised Vices": "Immoral practices" and "unnatural vice" in South African prisons and compounds, 1890-1920. Social Dynamics, v. 19, n. 2, p. 92-110, 1993. Disponível em: https://www.tandfonline.com/doi/ abs/10.1080/02533959308458553. Acesso em: 5 de maio de 2020.

ADERINTO, Saheed. When Sex Threatened the State: Illicit sexuality, nationalism, and politics in colonial Nigeria, 1900-1958. Champaign: University of Illinois Press, 2014.

ADICHIE, Chimamanda N. O Perigo de uma História Única. São Paulo: Companhia das Letras, 2019.

AGAMBEN, Giorgio. Homo Sacer: Sovereign Power and Bare Life. Stanford: Stanford University Press, 1995.

ALDRICH, Robert. Colonialism and Homosexuality. Londres: Routledge, 2003.

AMADIUME, Ifi. Male Daughters, Female Husbands: Gender and sex in an African society. Londres: Zed Books, 1987.

AMADIUME, Ifi. Re-Inventing Africa: Matriarchy, religion and culture. Londres: Zed Books, 1997.

AMADIUME, Ifi. Sexuality, African Religio-Cultural Traditions and Modernity: expanding the lens. CODESRIA Bulletin, n. 1-2, p. 26-28, 2006. Disponível em: http://www.arsrc. org/downloads/features/ amadiume.pdf. Acesso em: 5 de maio de 2020.

AMORY, Deborah P. "Homosexuality” in Africa: Issues and debates. Issue: A Journal of Opinion, v. 25, n. 1, p. 5-10, 1997. Disponível em: https://www.jstor.org/stable/1166238?seq=1. Acesso em: 5 de julho de 2020.

AMSELLE, Jean-Loup. L'Occident Decroché: Enquête sur les postcolonialismes. Paris: Pluriel, 2008.

ARNFRED, Signe (Org.). Re-Thinking Sexualities in Africa. Upsala: Nordiska Afrikainstitutet, 2004.

AWONDO, Patrick. Médias, Politique et Homosexualité au Cameroun. Retour sur la Construction d'une Controverse. Politique Africaine, v. 126, n. 2, p. 69-85, 2012. Disponível em: https://www.cairn.info/revue-politique-africaine-2012-2-page-69.htm. Acesso em: 5 de maio de 2020.

AWONDO, Patrick; GESCHIERE, Peter; REID, Graeme. Une Afrique Homophobe? Sur quelques trajectoires de politisations de l'homosexualité: Cameroun, Ouganda, Sénégal et Afrique du Sud. Raisons Politiques, v. 49, n. 1, p. 95-118, 2013. Disponível em: https://www.cairn.info/revue-raisons-politiques-2013-1-page-95.htm. Acesso em: 5 de maio de 2020.

BAKARE-YUSUF, Bibi. “Yorubas Don't Do Gender”: A critical review of Oyeronke Oyewumi's The Invention of Women: Making an African sense of western gender discourse. 
Fabiano Gontijo

African Identities, v. 1, n. 1, p. 119-140, 2003.

BALIBAR, Etienne. La Forme Nation: histoire et idéologie. In: Étienne Balibar \& Immanuel Wallerstein (Orgs.). Race, Nation, Classe: les identités ambiguës. Paris: La Découverte, 1988. p. 117-143.

BALLESTRIN, Luciana. Moralidade/Colonialidade sem "Imperialidade"? O Elo Perdido do Giro Decolonial. DADOS, v. 60, n. 2, p. 505-540, 2017.

BANCEL, Nicolas; BLANCHARD, Pascal; BOËTSCH, Gilles; DEROO, Éric; LEMAIRE, Sandrine. Zoos Humains. De la Vénus Hottentote aux reality show. Paris: La Découverte, 2002.

BANCEL, Nicolas; DAVID, Homas; THOMAS, Dominic (Orgs.). The Invention of Race: Scientific and popular representations. Londres: Routledge, 2014.

BLACKWOOD, Evelyn; WIERINGA, Saskia W. (Orgs.). Female Desires. New York: Columbia University Press. 1999.

BLANCHARD, Pascal. La Fracture Coloniale. Paris: La Découverte. 2005.

BLANCHARD, Pascal; BANCEL, Nicolas; BOËTSCH, Gilles; THOMAS, Dominic; TARAUD, Christelle (Orgs.). Sexe, Race et Colonie: La domination des corps du XVe siècle à nos jours. Paris: La Découverte, 2018.

BLANCKAERT, Claude. La Vénus Hottentote entre Barnum et Muséum. Paris: Muséum National d'Histoire Naturelle, 2014.

BLIDON, Marianne; ROUX, Sébastien. L'Ordre Sexuel du Monde. L'Espace Politique, v. 13, n. 1, s/p, 2011. Disponível em: https://journals.openedition.org/espacepolitique/1813. Acesso em: 5 de maio de 2020.

BOËTSCH, Gilles; BANCEL, Nicolas; BLANCHARD, Pascal; CHALAYE, Sylvie; ROBLES, Fanny; SHARPLEY-WHITING, Denean T.; STASZAK, Jean-François; TARAUD, Christelle; THOMAS, Dominic; YAHI, Naïma. Sexualités, Identités \& Corps Colonisés. Paris: CNRS, 2019.

BOËTSCH, Gilles; SAVARESE, Eric. Le Corps de l'Africaine. Érotisation et Inversion. Cahiers d'Études Africaines, v. 39, n. 153, p. 123-144, 1999. Disponível em: https:// www.persee.fr/doc/cea_0008-0055_1999_num_39_153_1967. Acesso em: 5 de maio de 2020.

BROQUA, Christophe. L'Émergence des Minorités Sexuelles dans l'Espace Public en Afrique. Politique Africaine, v. 126, n. 2, p. 5-23, 2012. Disponível em: https://www.cairn. info/revue-politique-africaine-2012-2-page-5.htm. Acesso em: 5 de maio de 2020.

BROQUA, Christophe; EBOKO, Fred. La Fabrique des Identités Sexuelles. Autrepart, v. 49, n. 1, p. 3-13, 2009. Disponível em: https://www.cairn.info/revue-autrepart-2009-1-page-3.htm. Acesso em: 5 de maio de 2020.

BURTON, Antoinette (Org.). Gender, Sexuality and Colonial Modernities. Londres: Routledge, 1999.

BUSSOTTI, Luca; TEMBE, António. A Homossexualidade na Conceção Afrocentrista de Molefi Kete Asante: entre libertação e opressão. Revista Ártemis, v. 17, n. 1, p. 15-24, 2014. Disponível em: https://periodicos.ufpb.br/ojs/index.php/artemis/article/ view/20084/11126. Acesso em: 5 de maio de 2020.

CARDOSO DE OLIVEIRA, Roberto. O Movimento dos Conceitos na Antropologia. Revista de Antropologia, n. 36, p. 13-31, 1993.

CARRIER, James G. (Org.). Occidentalism. Oxford: Claredon Press; Oxford University Press, 2003. 
Fabiano Gontijo

CASTRO-GÓMEZ, Santiago. El Tonto y los Canallas. Bogotá: Editorial Pontifícia Universidade Javeriana, 2019.

CHAKRABARTY, Dipesh. Habitations of Modernity: Essays in the wake of subaltern studies. Chicago: The University of Chicago Press, 2002.

CHAKRABARTY, Dipesh. Provincializing Europe. Princeton: Princeton University Press, 2007.

COLE, Catherine M.; MANUH, Takyiwaa; MIESCHER, Stephan M. (Orgs.). Africa After Gender? Indianapolis: Indiana University Press, 2007.

CURRIER, Ashley. Out in Africa: LGBT organizing in Namibia and South Africa. Minneapolis: University of Minnesota Press, 2012.

DABASHI, Hamid. Brown Skin, White Masks. Londres: Pluto Press, 2001.

DAS, Veena; POOLE, Deborah. State and Its Margins: Comparative Ethnographies. In: DAS, Veena; POOLE, Deborah (Orgs.). Anthropology in the Margins of State. New Delhi: Oxford University Press, 2004. p. 3-33.

DIAS, Juliana Braz; BELIZZE, Geovanna. Encenando a Diferença em Palcos Metropolitanos: As trajetórias de Sarah Baartman e Franz Taibosh. Anuário Antropológico, v. 45, n. 3, p. 304-324, 2020. Disponível em: https://doi.org/10.4000/aa.6697. Acesso em: 5 de maio de 2020.

DIESEL, Alleyn (Org.). Reclaiming the L-world: Sappho's daughters out in Africa. Cidade do Cabo: Modjaji Books, 2011.

DONHAM, Donald L. Freeing South Africa: The "modernization" of male-male sexuality in Soweto. Cultural Anthropology, v. 13, n. 1, p. 3-21, 1998. Disponível em: https:// www.jstor.org/stable/656686?seq=1. Acesso em: 5 de maio de 2020.

DORLIN, Elsa (Org.). Sexe, Race, Classe: Pour une épistémologie de la domination. Paris: PUF, 2009.

DORLIN, Elsa. La Matrice de la Race. Généalogie sexuelle et coloniale de la nation française. Paris: La Découverte, 2006.

DUDINK, Stefan. Les Nationalismes Sexuels et l'Histoire Raciale de l'Homosexualité. Raisons Politiques, v. 49, n. 1, p. 43-54, 2013. Disponível em: https://www.cairn.info/ revue-raisons-politiques-2013-1-page-43.htm. Acesso em: 5 de maio de 2020.

DURANTI, Andrea. 2008. Gay but Not Queer: Defining liminal post-queer identities in Maghrebian literature. Contemporary French and Francophone Studies, v. 12, n. 1, p. 79-87. Disponível em: https://www. tandfonline.com/doi/ abs/10.1080/17409290701793034?journalCode=gsit20. Acesso em: 5 de maio de 2020.

EKINE, Sokari. Narrativas Contestadoras da África Queer. Cadernos de Gênero e Diversidade, v. 2, n. 2, p. 10-14, 2016. Disponível em: https://portalseer.ufba.br/index.php/ cadgendiv/article/view/20727. Acesso em: 5 de maio de 2020.

EKINE, Sokari; ABBAS, Hakima (Orgs.). Queer African Reader. Oxford: Pambuzuka Press, 2013.

ELIAS, Norbert. O Processo Civilizador. Rio de Janeiro: Zahar, 1994.

ELLISON, Marvin M. Erotic Justice: A liberating ethic of sexuality. Louisville: Westminster John Knox Press, 1996.

EPPRECHET, Marc. Sexuality and Social Justice in Africa. Londres: Zed Books, 2013.

EPPRECHT, Marc. "Hidden" Histories of African Homosexualities. Canadian Woman Studies / Les Cahiers de la Femme, v. 24, n. 2-3, p. 138-144, 2005. Disponível em: https:// core.ac.uk/reader/230900048. Acesso em: 5 de maio de 2020. 
Fabiano Gontijo

EPPRECHT, Marc. Heterosexual Africa? The history of an idea from the age of exploration to the age of AIDS. Athens: Ohio University Press, 2008a.

EPPRECHT, Marc. Unspoken Facts: A history of homosexualities in Africa. Harare: Gays and Lesbians of Zimbabwe, 2008b.

EPPRECHT, Marc. New Perspectives on Sexualities in Africa: Introduction. Canadian Journal of African Studies, v. 43, n. 1, p. 1-7, 2009. Disponível em: https://www. tandfonline.com/doi/abs/10.1080/00083968.2010.9707579. Acesso em: 5 de maio de 2020.

EPPRECHT, Marc; MURRAY, Stephen O.; ANDAM, Kuukuwa; MIGUEL, Francisco; MBAYE, Aminate C.; GAUDIO, Rudolf P. Boy Wives, Female Husbands Twenty Years On: Reflections on scholarly activism and the struggle for sexual orientation and gender identity/expression rights in Africa. Canadian Journal of African Studies, v. 52, n. 3, p. 349-364, 2018. Disponível em: https://doi.org/10.1080/00083968.2018. 1546604. Acesso em: 5 de maio de 2020.

FANON, Frantz. Peau Noire, Masques Blancs. Paris: Seuil, 1952.

FAUSTO-STERLING, Anne. Sexing the Body: gender politics and the construction of sexuality. New York: Basic Books, 2000.

FERREIRA, Jonatas; HAMLIN, Cynthia. 2010. Mulheres, Negros e Outros Monstros: Um ensaio sobre corpos não civilizados. Revista Estudos Feministas, v. 18, n. 3, p. 811836. Disponível em: https://www.scielo.br/ pdf/ref/v18n3/v18n3a10.pdf. Acesso em: 5 de maio de 2020.

FOUCAULT, Michel. O Sujeito e o Poder. In: DREYFUS, Hubert; RABINOW, Paul (Orgs.). Michel Foucault - Uma trajetória filosófica. Rio de Janeiro: Forense, 1995. p. 229-249.

FOUCAULT, Michel. Microfísica do Poder. Rio de Janeiro: Graal, 1998.

FOUCAULT, Michel. História da Sexualidade. 1 A Vontade de Saber. Rio de Janeiro: Graal, 1999.

FOUCAULT, Michel. Sécurité, Territoire, Population. Cours au Collège de France (19771978). Paris: Gallimard; Seuil, 2004a.

FOUCAULT, Michel. Naissance de la Biopolitique. Cours au Collège de France (1978-1979). Paris: Gallimard; Seuil, 2004b.

GALZ - GAYS AND LESBIANS OF ZIMBABWE. Sahwira: Being gay and lesbian in Zimbabwe. Harare: GALZ, 1995.

GARGALLO, Francesca. Feminismo desde Abya Yala. Cidade do México: s/e, 2014.

GAUDIO, Rudi. Male Lesbians and Other Queer Notions in Hausa. In: Stephen O. Murray \& Will Roscoe (Orgs.). Boy Wives and Female Husbands: Studies in African homosexualities. New York: St. Martin's Press, 1998. p. 111-128.

GAUDIO, Rudolf P. Allah Made Us: Sexual outlaws in an Islamic African city. Malden: Wiley-Blackwell. 2009.

GEVISSER, Mark; CAMERON, Edwin (Orgs.). Defiant Desire: Gay and lesbian lives in South Africa. New York: Routledge, 1995.

GILROY, Paul. O Atlântico Negro. São Paulo: Ed. 34, 2001.

GONTIJO, Fabiano. Intersexualidade, Bioantropologia/Bioarqueologia e Poder. Bagoas, v. 12, n. 18, p. 48-73, 2018. Disponível em: https://periodicos.ufrn.br/bagoas/article/ view/14403. Acesso em: 5 de maio de 2020.

GONTIJO, Fabiano; ARISI, Barbara; FERNANDES, Estêvão. Queer Natives in Latin America. Cham: Springer, 2021. 
GONTIJO, Fabiano; SCHAAN, Denise. Sexualidade e Teoria Queer: Apontamentos para a arqueologia e a antropologia brasileiras. Revista de Arqueologia, v. 30, n. 2, p. 51-70. 2017. Disponível em: https://revista. sabnet.org/index.php/SAB/article/view/544. Acesso em: 5 de maio de 2020.

GORDON-CHIPEMBERE, Natasha (Org.). Representation and Black Womanhood: The legacy of Sarah Baartman. New York: Palgrave Macmillan, 2011.

GUEBEGUO, Charles. L'Homosexualité en Afrique: Sens et variations d'hier à nos jours. Socio-Logos, n. 1, s/p, 2006a. Disponível em: https://journals.openedition.org/socio-logos/37. Acesso em: 5 de maio de 2020.

GUEBEGUO, Charles. La Question Homosexuelle en Afrique: Le cas du Cameroun. Paris: L'Harmattan, 2006b.

GUEBOGUO, Charles. Les Sexualités Africaines dans leurs Nouvelles Perspectives: Introduction. Canadian Journal of African Studies, v. 43, n. 1, p. 8-11, 2009. Disponível em: https://www.tandfonline.com/doi/abs/ 10.1080/00083968.2010.9707580. Acesso em: 5 de maio de 2020.

GUNKEL, Henriette. The Cultural Politics of Female Sexuality in Africa. New York: Routledge, 2010.

GUNKEL, Henriette. Some Reflections on Postcolonial Homophobia, Local Interventions, and LGBTI Solidariy Online: The politics of global petitions. African Studies Review, v. 56, n. 2, p. 67-81, 2013. Disponível em: https://muse.jhu.edu/article/519184. Acesso em: 5 de maio de 2020.

HAN, Enze; O'MAHONEY, Joseph. British Colonialism and the Criminalization of Homosexuality: Queens, crime and empire. Londres: Routledge, 2018.

HAYES, Jarrod. Queer Nations: Marginal sexualities in the Maghreb. Chicago: University of Chicago Press, 2000.

HERDT, Gilbert (Org.). Moral Panics, Sex Panics. New York: New York University Press, 2009.

HOAD, Neville. African Intimacies: Race, homosexuality, and globalization. Minneapolis: University of Minnesota Press, 2007.

HOLMES, Rachel. African Queen: The real life of the Hottentot Venus. New York: Penguin Random, 2009.

HYAM, Ronald. Empire and Sexual Opportunity. Manchester: Manchester University Press, 1991.

IRELAND, Patrick R. A Macro-Level Analysis of the Scopes, Causes, and Consequences of Homophobia in Africa. African Studies Review, v. 56, n. 2, p. 47-66, 2013. Disponível em: https://muse.jhu.edu/article/ 519183. Acesso em: 5 de maio de 2020.

IZUGBARA, C. Otutubikey. Patriarchal ideology and Discourses of sexuality in Nigeria. Understanding Human Sexuality Seminar Series 2. Lagos: ARSRC, 2004. Disponível em: http://www.arsrc.org/downloads/ uhsss/izugbara.pdf. Acesso em: 5 de maio de 2020.

JACKSON, Peter A. Global Queering and Global Queer Theory: Thai (trans)genders and (homo)sexualities in world history. Autrepart, v. 49, n. 1, p. 15-30, 2009. Disponível em: https://www.cairn.info/revue-autrepart-2009-1-page-15.htm. Acesso em: 5 de maio de 2020. 
Fabiano Gontijo

JAUNAIT, Alexandre; LE RENARD, Amélie; MARTEAU, Élisabeth. Nationalismes Sexuels? Reconfigurations contemporaines des sexualités et des nationalismes. Raisons Politiques, v. 49, n. 1, p. 5-23, 2013. Disponível em: https://www.cairn.info/revue-raisons-politiques-2013-1-page-5.htm. Acesso em: 5 de maio de 2020.

JUNGAR, Katarina; OINAS, Elina. Preventing HIV? Medical Discourses and invisible women. In: ARNFRED, Signe (Org.). Re-Thinking Sexualities in Africa. Upsala: Nordiska Afrikainstitutet, 2004. p. 97-114.

KAOMA, Kapya. Globalizing the Culture Wars: American conservatives, African churches and homophobia. Somerville: Political Research Associates, 2009.

KAPUR, Ratna. Erotic Justice: Law and the new politics of postcolonialism. Londres: Glasshouse Press, 2005.

KROUSE, Matthew (Org.). The Invisible Ghetto: Lesbian \& gay writing from South Africa. Joanesburgo: COSAW, 1993.

LACHHEB, Monia (Org.). Être Homosexuel au Maghreb. Paris: Karthala, 2016.

LANDER. Edgardo. A Colonialidade do Saber. Buenos Aires: CLACSO, 2005.

LANGA, Ercílio Neves B. A Homossexualidade no Continente Africano: História, colonização e debates contemporâneos. Cadernos de África Contemporânea, v. 1, n. 2, p. 52-72, 2018. Disponível em: http://www.capoeirahumanidadeseletras.com.br/ojs2.4.5/index.php/cac/article/view/145. Acesso em: 5 de maio de 2020.

LARMARANGE, Joseph; DESGRÉES DU LOU, Annabel; ENEL, Catherine; WADE, Abdoulaye. Homosexualité et Bisexualité au Sénégal. Population, 64 (4): 723-56. 2009. Disponível em: https://www.jstor.org/stable/ 40608431?seq=1. Acesso em: 5 de maio de 2020

LEVINE, Philippa (Org.). Gender and Empire. Oxford: Oxford University Press, 2007.

LIMA, Fátima. Bio-Necropolítica. Arquivos Brasileiros de Psicologia, v. 70 (no.spe.), p. 20-33, 2018. Disponível em: http://pepsic.bvsalud.org/scielo.php?script=sci_arttext\&pid=S1809-52672018000400003\& lng=pt\&nr m=iso\&tlng=pt. Acesso em: 5 de maio de 2020 .

LOOMBA, Ania; KAUL, Suvir; BUNZI, Matti; BURTON, Antoinette; ESTY, Jed (Orgs.). Postcolonial Studies and Beyond. Durham: Duke University Press, 2005.

M'BAYE, Babacar. The Origins of Senegalese Homophobia: Discourses on homosexuals and transgender people in colonial and postcolonial Senegal. African Studies Review, v. 56, n. 2, p. 109-128, 2013. Disponível em: https://muse.jhu.edu/article/519186. Acesso em: 5 de maio de 2020.

MAFEJE, Archie. Anthropology in Post-Independence Africa. Nairobi: Heinrich Böll Foudantion, 2001.

MAFEJE, Archie. A Commentary on Anthropology and Africa. Codesria Bulletin, n. 3-4, p. 88-94, 2008. Disponível em: https://www.codesria.org/spip.php?article508\&lang=en. Acesso em: 5 de maio de 2020.

MALDONADO-TORRES, Nelson. Analítica da Colonialidade e da Decolonialidade. In: BERNARDINO-COSTA, Joaze; MALDONADO-TORRES, Nelson; GROSFOGUEL, Ramón (Orgs.). Decolonialidade e Pensamento Afro-Diaspórico. Belo Horizonte: Autêntica, 2018. p. 27-54.

MALOMALO, Bas'llele. Decolonialidade Africana/Negra: Uma crítica pan-africana construtiva. Capoeira, v. 5, n. 2, p. 115-140, 2019. Disponível em: http://www.capoeirahumanidadeseletras.com.br/ojs-2.4.5/index. php/capoeira/article/view/211 
MARTIN, Karin; MAKHOSAZANA, Xaba (Orgs.). Queer Africa: New and collected fiction. Joanesburgo: MaThoko's Brooks, 2013.

MASSAD, Joseph. Re-Orienting Desire: The Gay International and the arab world. Public Culture, v. 14, n. 2, p. 361-85, 2002. Disponível em: https://muse.jhu.edu/article/26284. Acesso em: 5 de maio de 2020.

MASSAD, Joseph. Desiring Arabs. Chicago: University of Chicago Press, 2007.

MATEBENI, Zethu (Org.). Reclaiming Afrikan: Queer perspectives on sexual and gender identities. Athlone: Modjaji Books, 2014.

MATEBENI, Zethu. Exploring Black Lesbian Sexualities and Identities in Johannesburg. Tese (Doutorado em Filosofia) - University of Witwatersrand, Joanesburgo, 2011.

MATEBENI, Zethu; MONRO, Surya; REDDY, Vasu (Orgs.). Queer in Africa: LGBTQI identities, citizenship, and activism. Londres: Routledge, 2018.

MBEMBE, Achille. À Propos des Écritures Africaines de Soi. Politique Africaine, n. 77, p. 16-43, 2000. Disponível em: https://www.cairn.info/revue-politique-africaine-2000-1-page-16.htm. Acesso em: 5 de maio de 2020.

MBEMBE, Achille. De La Postcolonie: Essai sur l'imagination politique dans l'Afrique contemporaine. Paris: Karthala, 2005.

MBEMBE, Achille. Le Potentat Sexuel: À propos de la sodomie, de la fellation et autres privautés postcoloniales. Le Messager / Africultures, 13/02/2006, s/p. Disponível em: http://africultures.com/le-potentat-sexuel-a-propos-de-la-sodomie-de-la-fellationet-autres-privautes-postcoloniales-4296/. Acesso em: 5 de maio de 2020.

MBEMBE, Achille. Necropolítica. São Paulo: n-1 Edições, 2018.

MBISI, Thabo. The Lies We Have Been Told: On (homo)sexuality in Africa. Africa Today, v. 58, n. 1, p. 54-77, 2011. Disponível: http://web-b-ebscohost. ez3.periodicos.capes.gov.br/ehost/detail/detail?vid=3\&sid=a71135cf-c71b-4876-8de0-0717d0775abe\%40pdc-v-sessmgr04\&bdata=Jmxhbmc9cHQtYnlmc2l0ZT1laG9z dC1saXZI\#AN=66358070\&db=sih. Acesso em: 5 de maio de 2020.

MBURU, John. Awakenings: Dreams and delusions of an incipient lesbian and gay movement in Kenya. In: Peter Drucker (Org.). Different Rainbows. Londres: Gay Men's Press, 2000. p. 179-191.

McCLINTOK, Anne. Imperial Leather: Race, gender, and sexuality in the colonial conquest. New York: Routledge, 1995.

MIESCHER, Stephan F. Making Men in Ghana. Indianapolis: Indiana University Press, 2005.

MIGNOLO, Walter (Org.). Género y Descolonialid. Buenos Aires: Ediciones del Siglo, 2008.

MIGNOLO, Walter. The Darker Side of Western Modernity: Global futures, decolonial options. Durham; Londres: Duke University Press, 2011.

MIGUEL, Francisco. "Levam Má Bô”: (Homo)sexualidades entre os sampadjudus da Ilha de São Vicente de Cabo Verde. Dissertação (Mestrado em Antropologia Social) -Universidade de Brasília, Brasília, 2014.

MIGUEL, Francisco. "Hiprocrisia”: A visão dos gays cabo-verdianos sobre o seu próprio sistema de gênero. ACENO: Revista de Antropologia do Centro-Oeste, v. 3, n. 5, p. 259 276, 2016a. Disponível em: http://periodicoscientificos.ufmt.br/ojs/index.php/aceno/ article/view/3276. Acesso em: 5 de maio de 2020.

MIGUEL, Francisco. (Homo)Sexualidades Masculinas em Cabo Verde: Um caso para 
pensar teorias antropológicas e movimento LGBT em África. Enfoques, v. 15, n. 1, p. 87-110, 2016b. Disponível em: https://revistas.ufrj.br/index.php/enfoques/issue/ view/847/showToc. Acesso em: 5 de maio de 2020.

MIGUEL, Francisco. Maríyarapaxjis: Silêncio, exogenia e tolerância nos processos de institucionalização das homossexualidades masculinas em Moçambique. Tese (Doutorado em Antropologia Social) - Universidade de Brasília, Brasília, 2019.

MORGAN, Ruth; WIERINGA, Saskia (Orgs.). Tommy Boys, Lesbian Men, and Ancestral Wives: Female same-sex practices in Africa. Joanesburgo: Jacana, 2005.

MOUTINHO, Laura. Cooperação Internacional, Parcerias Acadêmicas e Afeto na Perspectiva Sul-Sul. Revista Estudos Feministas, v. 27, n. 3, p. 1-9, 2019. Disponível em: https://www.jstor.org/stable/ 26851993?seq=1. Acesso em: 5 de maio de 2020.

MUDIMBE, Valentin-Yves. A Invenção da África. Luanda: Pedago, 2013.

MURRAY, Stephen O. (Org.). Latin American Male Homosexualities. Albuquerque: University New Mexico Press, 1995.

MURRAY, Stephen O.; ROSCOE, Will. Islamic Homosexualities. New York: New York University Press, 1997.

MURRAY, Stephen O.; ROSCOE, Will. Boy Wives and Female Husbands: Studies in African homosexualities. New York: St. Martin's Press, 1998.

N'DIAYE, Tidiane. La Longue Marche des Peuples Noirs. Paris: Publibook, 2006.

NDJIO, Basile. Post-Colonial Histories of Sexuality: The political invention of a libidinal African straight. Africa: The Journal of the International Institute, v. 82, n. 4, p. 609631, 2012. Disponível em: https://www.cambridge.org/core/journals/africa/article/ postcolonial-histories-of-sexuality-the-political-invention-of-a-libidinal-african-straight/667F1D4787779B54B0CABBBEF8A90490. Acesso em: 5 de maio de 2020.

NIANG, Cheikh Ibrahim; DIAGNE, Moustapha; NIANG, Youssoupha; MOREAU, Amadou Mody (Orgs.). Meeting the Sexual Health Needs of Men Who Have Sex with Men in Senegal. Washington: USAID, 2002.

NKOLI, Simon. Wardrobes: Coming out as a black gay activist in South Africa. In: GEVISSER, Mark; CAMERONB, Edwin (Orgs.). Defiant Desire: Gay and lesbian lives in South Africa. Joanesburgo: Ravan, 1994. p. 249-257.

NYANZI, Stella. Unpacking the [Govern]Mentality of African Sexualities. In: TAMALE, Sylvia (Org.). African Sexualities: A reader. Cidade do Cabo: Pambazuka, 2011. p. 477-501.

NYECK, Sybille N.; EPPRECHT, Marc. Sexual Diversity in Africa: Politics, theory, citizenship. Montréal: McGill-Queen's University Press, 2013.

OMBOLO, J.-P. Sexe et Société en Afrique Noire. Paris: L’Harmattan, 1990.

OYĚWÙMÍ, Oyèrònké. The Invention of Women: Making an African sense of western gender discourse. Minneapolis: University of Minnesota Press, 1997.

PEIRETTI-COURTIS, Delphine. Sexe, Race et Médecine: Anatomie et sexualité des Africain-e-s sous l'oeil des médecins français (1780-1950). Emulations, n. 15, p. 4558, 2015. Disponível em: https://ojs.uclouvain.be/ index.php/emulations/article/ view/4963. Acesso em: 5 de maio de 2020.

PUAR, Jasbir K. Terrorist Assemblage: homonationalism in queer times. Durham: Duke University Press, 2007.

PURI, Jyoti. Encountering Nationalism. Malden: Blackwell Publishing, 2004.

QUIJANO, Aníbal. Colonialidad del Poder y Clasificación Social. Journal of World-Sys- 
tems Research, v. 6, n. 2, p. 342-386, 2000. Disponível em: http://jwsr.pitt.edu/ojs/ jwsr/article/view/228. Acesso em: 5 de maio de 2020.

QURESHI, Sadiah. Displaying Sarah Baartman, the "Hottentot Venu". History of Science, v. 42, n. 2, p. 233-257, 2004. Disponível em: https://journals.sagepub.com/doi/ pdf/10.1177/007327530404200204. Acesso em: 5 de maio de 2020.

RATELE, Kopana. Analysing Males in Africa: Certain useful elements in considering ruling masculinities. African and Asian Studies, v. 7, n. 4, p. 515-536, 2008. Disponível em: https://www.deepdyve. com/lp/brill/analysing-males-in-africa-certain-useful-elements-in-considering-elgWLNtKJt?key=brill. Acesso em: 5 de maio de 2020.

REA, Caterina. Sexualidades Dissidentes e Teoria Queer Pós-Colonial: 0 caso africano. Epistemologias do Sul, v. 1, n. 1, p. 145-165, 2017. Disponível em: https://revistas.unila.edu.br/epistemologiasdosul/article/ view/ 775. Acesso em: 5 de maio de 2020.

REA, Caterina. Narrativas e Contra-Narrativas Africanas sobre a Dissidência Sexual. Capoeira, v. 5, n. 2, p. 142-154, 2019. Disponível em: http://www.capoeirahumanidadeseletras.com.br/ojs-2.4.5/index.php/ capoeira/article/view/212

REA, Caterina; FONSECA, João Bosco S.; SILVA, Ana C. B. B. (Orgs.). Traduzindo a África Queer II. Salvador: Devires, 2020.

REA, Caterina; PARADIS, Clarisse G.; AMANCIO, Izzie M. S. (Orgs.). Traduzindo a África Queer. Salvador: Devires, 2018.

READ, Graeme. How to Be a "Real Gay": Gay identities in small-town South Africa. Scottsville: KwaZulu-Natal Press, 2013.

REBUCINI, Gianfranco. Les Masculinités au Maroc. Pour une Anthropologie des Genres et des Sexualités dans la Ville de Marrakech. Tese (Doutorado em Etnologia e Antropologia Social) - École de Hautes Études en Sciences Sociales - EHESS, Paris, 2009.

REBUCINI, Gianfranco. 2013. Masculinités Hégémoniques et « Sexualités » entre Hommes au Maroc. Cahiers d'Études Africaines, v. 209/210, n. 1-2, p. 387-415, 2013. Disponível em: https://journals. openedition.org/etudesafricaines/17367. Acesso em: 5 de maio de 2020.

REDDY, Vasu; SANDFORT, Theo; RISPEL, Laetitia (Orgs.). From Social Silence to Social Science: Same-sex sexuality, HIV \& AIDS and Gender in South Africa. Cidade do Cabo: HSRC, 2009.

RESTREPO, Eduardo; ESCOBAR, Arturo. "Other Anthropology and Anthropology Otherwise": steps to a world anthropologies framework. Critique of Anthropology, v. 25, n. 2, p. 99-129, 2005. Disponível em https://journals.sagepub.com/ doi/10.1177/0308275X05053009. Acesso em: 5 de maio de 2020.

SAID, Edward. Orientalismo. São Paulo: Companhia das Letras, 1990.

SANDFORT, Theo; SIMENEL, Fabienne; MWACHIRO, Kevin; REDDY, Vasu (Orgs.). Boldly Queer: African perspectives on same-sex sexuality and gender diversity. Amsterdam: Hivos, 2015.

SANTOS, Boaventura de Sousa. Para Além do Pensamento Abissal. Revista Crítica de Ciências Sociais, n. 78, p. 3-46, 2007.

SAVARESE, Eric. Domination Coloniale, Violence Physique et Violence Symbolique. Revue Méditerranéenne d'Études Politiques, n. 3, p. 121-138, 1996.

SCHMITT, Arno; SOFER, Jehoeda (Orgs.). Sexuality and Eroticism in Moslem Societies. New York: Routledge, 2013 [1992]. 
Fabiano Gontijo

SEDGWICK, Eve K. Epistemology of the Closet. Berkeley: University of California Press, 1990.

SPRONK, Rachel. Ambiguous Pleasure: Sexuality and middle-class self-perceptions in Nairobi. New York: Berghahn Books, 2012.

SPRONK, Rachel; HENDRIKS, Thomas. Readings in Sexualities from Africa. Bloomington: Indiana University Press, 2020.

STOLER, Ann L. Race and the Education of Desire: Foucault's History of Sexuality and the colonial orders of things. Durham: Duke University Press, 1995.

STOLER, Ann L. Carnal Knowledge and Imperial Power: Race and the intimate in colonial rule. Berkeley: University of California Press, 2002.

TAMALE, Sylvia (Org.). African Sexualities: A reader. Cidade do Cabo: Pambazuka Press, 2011.

TAMALE, Sylvia. Homosexuality: Perspectives from Uganda. Kampala: Fountain Publishers, 2007.

TAMALE, Sylvia. Confronting the Politics of Nonconforming Sexualities in Africa. African Studies Review, v. 56, n. 2, p. 31-45, 2013. Disponível em: https://www.cambridge.org/ core/journals/african-studies-review/article/confronting-the-politics-of-nonconforming-sexualities-in-africa/ E2E9BC2E3CFE66C5CDC848EE2C7BC275. Acesso em: 5 de maio de 2020.

TEUNIS, Niels. Same-Sex Sexuality in Africa: A case study from Senegal. AIDS and Behavior, v. 5, n. 2, p. 173-82, 2001. Disponível em: https://link.springer.com/article/10.1023/A:1011335129358. Acesso em: 5 de maio de 2020.

TRABELSI, Salah. L'Esclavage dans l'Orient Musulman au ler/VIle et IVe/Xe siècles. In: COTTIAS, Myriam; CUNIN, Elisabeth; MENDES, António de A. (Orgs.). Les Traites et les Esclavages. Paris: Karthala, 2010.

TRABELSI, Salah. Travail et Esclavage: Y a-t-il eu un modèle oriental? Rives Méditerranéennes, n. 53, p. 21-39, 2016. Disponível em: https://www.cairn.info/revue-rives-mediterraneennes-2016-2.htm. Acesso em: 5 de maio de 2020.

TUCKER, Andrew. Queer Visibilities: Space, identity and interaction in Cape Town. Malden: Wiley-Blackwell, 2009.

VANITA, Ruth. Queering India: Same-sex love and eroticism in Indian culture and society. Londres: Routledge, 2002.

WALLERSTEIN, Immanuel. Comprendre le Monde: introduction à l'analyse des systèmes-monde. Paris: La Découverte, 2006.

WIERINGA, Saskia; SIVORÍ, Horacio (Orgs.). The Sexual History of the Global South: Sexual politics and postcolonialism in Africa, Asia and Latin America. Londres: Zed Books, 2013.

WOLTERSDOFF, Volker. Neoliberalism and Its Homophobic Discontents. InterAlia: Pismo Poświęcone Studiom Queer, n. 2, p. 1-8, 2006-2007. Disponível em: https://interalia. queerstudies.pl/en/issue-2-2007/. Acesso em: 5 de maio de 2020. 